2001s-57

\title{
The Unreliability of Output Gap Estimates in Real Time
}

\author{
Athanasios Orphanides,
}

Simon van Norden

Série Scientifique

Scientific Series

Novembre 2001 


\section{CIRANO}

Le CIRANO est un organisme sans but lucratif constitué en vertu de la Loi des compagnies du Québec. Le financement de son infrastructure et de ses activités de recherche provient des cotisations de ses organisationsmembres, d'une subvention d'infrastructure du ministère de la Recherche, de la Science et de la Technologie, de même que des subventions et mandats obtenus par ses équipes de recherche.

CIRANO is a private non-profit organization incorporated under the Québec Companies Act. Its infrastructure and research activities are funded through fees paid by member organizations, an infrastructure grant from the Ministère de la Recherche, de la Science et de la Technologie, and grants and research mandates obtained by its research teams.

\section{Les organisations-partenaires / The Partner Organizations}

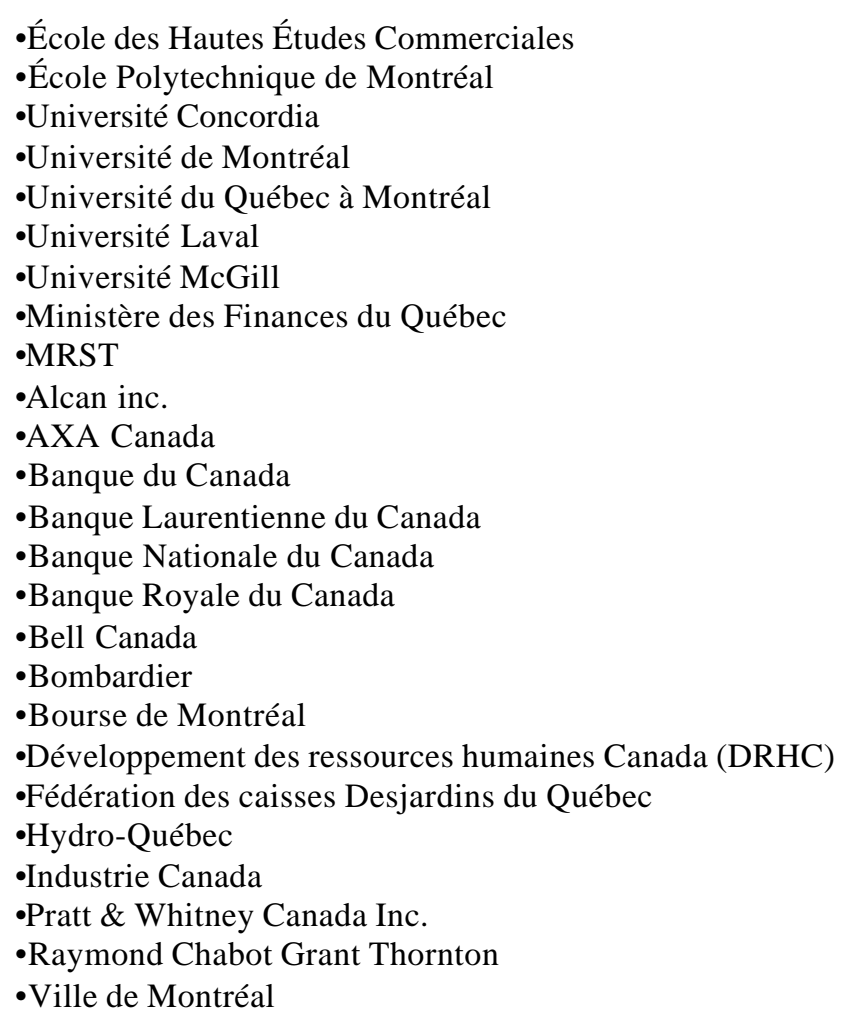

(C) 2001 Athanasios Orphanides et Simon van Norden Tous droits réservés. All rights reserved.

Reproduction partielle permise avec citation du document source, incluant la notice (C)

Short sections may be quoted without explicit permission, if full credit, including ( notice, is given to the source.

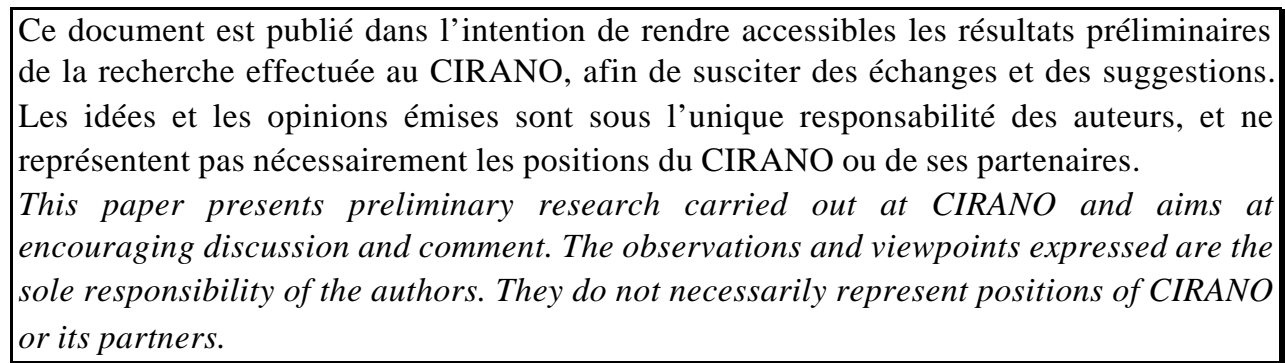




\title{
The Unreliability of Output Gap Estimates in Real Time*
}

\author{
Athanasios Orphanides ${ }^{\dagger}$ et Simon van Norden
}

\begin{abstract}
Résumé / Abstract
Nous examinons la fiabilité de plusieurs méthodes qui sont utilisés pour rendre des séries chronologiques stationnaires, en portant une attention particulière à la précision des estimations en temps réel de l'écart de la production. Nous montrons que de la taille des révisions ex post de nos estimations de l'écart et celle des estimations faites en temps réels sont du même ordre de grandeur et que ces révisions sont fortement persistantes. Même si elle est importante, la révision des données n'est pas la source principale des révisions des estimations. La majorité de ce problème est due à la forte imprécision des estimations des tendances actuelles de la production. Des techniques multivariés, qui exploitent aussi le taux d'inflation pour estimer l'écart de la production, ne sont pas plus précises que leurs équivalents univariés.

We examine the reliability of alternative output detrending methods, with special attention to the accuracy of real-time estimates of the output gap. We show that ex post revisions of the estimated gap are of the same order of magnitude as the estimated gap itself and that these revisions are highly persistent. Although important, the revision of published data is not the primary source of revisions in measured output gaps; the bulk of the problem is due to the pervasive unreliability of end-of-sample estimates of the trend in output. Multivariate methods that incorporate information from inflation to estimate the output gap are not more reliable than their univariate counterparts.
\end{abstract}

Mots clés : données en temps réels, l'écart de la production, l'estimation du cycle d'affaire

Keywords : Real-time data, output gap, business cycle measurement

JEL : C4, E32.

\footnotetext{
* Correspondence : Athanasios Orphanides: Division of Monetary Affairs, Board of Governors of the Federal Reserve System, Washington, D.C. 20551, USA. Tel.: (202) 452-2654, e-mail: aorphanides@ frb.gov.

Simon van Norden : Service d'enseignement de la finance, H.E.C., 3000 Chemin de la Côte Sainte Catherine, Montréal, QC, Canada H3T 2A7. Tel.: (514)340-6781, e-mail: simon.van-norden@ hec.ca.

We would like to thank Bryan Campbell, Andy Filardo and Tiff Macklem, as well as discussants and seminar participants at the Atelier économétrique de Montréal, the Centre for Growth and Business Cycle Research at the University of Manchester, the University of Ottawa, les Journées d'Optimization de Montréal, the World Congress of the Econometric Society in Seattle, the meetings of the American Economic Association and Canadian Economics Association, the editor and our referees for their comments. Prof. van Norden would also like to thank the SSHRC and the HEC for their financial support. The opinions expressed are those of the authors and do not necessarily reflect views of the Board of Governors of the Federal Reserve System.

${ }^{\dagger}$ Board of Governors of the Federal Reserve System

${ }^{\ddagger}$ HEC Montréal et CIRANO
} 


\section{Introduction}

Understanding macroeconomic fluctuations entails the study of an economy's output relative to its trend or potential level. The difference between the two is commonly referred to as the business cycle or the output gap. Although macroeconomic analysis often takes measurement of the output gap for granted, its construction is subject to considerable uncertainty. As a practical matter, empirical estimates of the output gap for any given method may not be particularly reliable. This may pose an acute difficulty for economic stabilization policy that requires reliable estimates of the output gap in real time when policy decisions are made.

Three distinct issues complicate measurement of the output gap in real time. First, output data may be revised, implying that output gaps estimated from real-time data may differ from those estimated from data for the same period published later. Second, as data on output in subsequent quarters become available, hindsight may clarify our position in the business cycle even in the absence of data revision. Third, the arrival of new data may instead make us revise our model of the economy which in turn revises our estimated output gaps.

This paper investigates the relevance of these issues for the measurement of the output gap in the United States since the 1960s using several well-known detrending methods. ${ }^{1}$ For each method, we examine the behavior of end-of-sample output gap estimates and of the revisions of these estimates over time. We also decompose the revisions into their various sources, including that due to revisions of the underlying output data and that due to

\footnotetext{
${ }^{1}$ An early exposition of issues pertaining to estimating trends appeared in the inaugural issue of this Review, Persons (1919). The potential quantitative relevance of the issues we investigate has been pointed out before. Kuttner (1994) and St-Amant and van Norden (1998) pointed out that differences between endsample and mid-sample estimates of the output gap can differ substantially for some commonly used methods for estimating the output gap. Orphanides $(1998,2000)$ documented that the errors in "official" estimates of the output gap available to policymakers have indeed been substantial and several authors, including Kuttner (1992), McCallum and Nelson (1999), Orphanides (1998, 2001) and Smets (1998) have elaborated on the policy implications of this issue. This study is the first to assess and decompose the measurement errors associated with several techniques and is the first to assess these techniques with real-time data.

This issue also closely relates to investigations of uncertainty regarding estimation of the "unemployment gap," that is, the difference between the actual rate of unemployment and estimates of the natural rate of unemployment. Staiger, Stock and Watson (1997a,b) document that these estimates are very imprecise, which parallels the unreliability of the output gaps we discuss here.
} 
re-estimation of the process generating potential output.

Presuming that revisions "improve" our estimates, the total amount of revision gives us a lower bound on the measurement error thought to be associated with real-time output gaps. This is informative when and if we find that revision errors are relatively large since we can conclude that the total error of these estimators must be larger still. Furthermore, our results are quite general; they apply regardless of whether output gaps are used to cyclically-adjust budget balances, to forecast inflation or for other purposes, and do not require a priori assumptions on the true structure of the economy or on the true time-series model generating observed output.

\section{Alternative Detrending Methods}

A detrending method decomposes the log of real output, $q_{t}$, into a trend component, $\mu_{t}$, and a cycle component, $z_{t}$.

$$
q_{t}=\mu_{t}+z_{t}
$$

Some methods use the data to estimate the trend, $\mu_{t}$, and define the cyclical component as the residual. Others specify a dynamic structure for both the trend and cycle components and estimate them jointly. We examine detrending methods that fall into both categories.

\section{A. Deterministic Trends}

The first set of detrending methods we consider assume that the trend in (the logarithm of) output is well approximated as a simple deterministic function of time. The linear trend is the oldest and simplest of these models and the quadratic trend is a popular simple extension.

Because of the noticeable downturn in GDP growth after 1973, another simple deterministic technique is a breaking linear trend that allows for the slowdown in that year. Our implementation of the breaking trend method will incorporate the assumption that the location of the break is fixed and known. Specifically we assume that a break in the trend at the end of 1973 would have been incorporated in real time from 1977 on. This conforms 
with the debate regarding the productivity slowdown during the 1970s and evidence (e.g. Council of Economic Advisers, 1977) that it would not have been reasonable to introduce the 1973 break earlier but would be appropriate to do so as early as $1977 .^{2}$

\section{B. Unobserved Component Models and the Hodrick-Prescott Filter}

Unobserved component (UC) models offer a general framework for decomposing output into an unobserved trend and a cycle, allowing for an assumed dynamic structure for these components.

This framework can also nest smoothing splines, such the popular filter proposed by Hodrick and Prescott (1997) (the HP filter). ${ }^{3}$ We implement the HP filter, following Harvey and Jaeger (1993) and King and Rebelo (1993), by writing it in its unobserved components form. Assuming that the trend in (1) follows:

$$
(1-L)^{2} \mu_{t}=\eta_{t}
$$

the HP filter is obtained from (1) and (2) under the assumption that $z_{t}$ and $\eta_{t}$ are mutually uncorrelated white noise processes with a fixed relative variance $q$. We set $q$ to correspond to the standard application of the HP filter with a smoothing parameter of 1600 .

UC models also permit more complex dynamics to be estimated, and we examine two such alternatives, by Watson (1986) and by Harvey (1985) and Clark (1987). The Watson model modifies the linear level model to allow for greater business cycle persistence. Specifically, it models the trend as a random walk with drift and the cycle as an $\operatorname{AR}(2)$ process:

$$
\begin{gathered}
\mu_{t}=\delta+\mu_{t-1}+\eta_{t} \\
z_{t}=\rho_{1} \cdot z_{t-1}+\rho_{2} \cdot z_{t-2}+\varepsilon_{t}
\end{gathered}
$$

\footnotetext{
${ }^{2}$ We also investigated alternatives, including ones with a break of unknown location and also the possibility of multiple breaks. Qualitatively, the results were similar for the other alternatives. We also used Bai-Perron tests to determine when an econometrician would have been able to detect the change in trend and obtained similar conclusions.

${ }^{3}$ The development of smoothing splines dates back to the work of Whittaker (1923) and Henderson (1924) and discussion of its use for measuring business cycles may be found in Orphanides and van Norden (1999).
} 
Here $\varepsilon_{t}$ and $\eta_{t}$ are assumed to be i.i.d mean-zero Gaussian and mutually uncorrelated and $\delta$, $\rho_{1}$ and $\rho_{2}$, and the variances of the two shocks are parameters to be estimated ( 5 in total).

The Harvey-Clark model similarly modifies the local linear trend model:

$$
\begin{gathered}
\mu_{t}=g_{t-1}+\mu_{t-1}+\eta_{t} \\
g_{t}=g_{t-1}+\nu_{t} \\
z_{t}=\rho_{1} \cdot z_{t-1}+\rho_{2} \cdot z_{t-2}+\varepsilon_{t}
\end{gathered}
$$

Here $\eta_{t}, \nu_{t}$, and $\varepsilon_{t}$ are assumed to be i.i.d mean-zero Gaussian and mutually uncorrelated processes and $\rho_{1}$ and $\rho_{2}$ and the variances of the three shocks are parameters to be estimated (5 in total).

\section{Unobserved Component Models with a Phillips Curve}

Multivariate formulations of UC models attempt to refine estimates of the output gap by incorporating information from other variables linked to the gap. However, they also introduce additional sources of misspecification and parameter uncertainty which may offset potential improvements. To examine this issue, we consider two models which add a Phillips curve to the univariate formulations described above; those of Kuttner (1994) and Gerlach and Smets (1997).

Let $\pi_{t}$ be the quarterly rate of inflation. The Kuttner model adds the following Phillips curve equation to the Watson model:

$$
\Delta \pi_{t}=\xi_{1}+\xi_{2} \cdot \Delta q_{t}+\xi_{3} \cdot z_{t-1}+e_{t}+\xi_{4} \cdot e_{t-1}+\xi_{5} \cdot e_{t-2}+\xi_{6} \cdot e_{t-3}
$$

The Gerlach-Smets model modifies the Harvey-Clark model by adding a similar Phillips curve:

$$
\Delta \pi_{t}=\phi_{1}+\phi_{2} \cdot z_{t}+e_{t}+\phi_{3} \cdot e_{t-1}+\phi_{4} \cdot e_{t-2}+\phi_{5} \cdot e_{t-3}
$$

In each case the shock $e_{t}$ is assumed i.i.d. mean zero and Gaussian. In the Gerlach-Smets model, $e_{t}$ is also assumed uncorrelated with shocks driving the dynamics of the trend and 
cycle components of output in the model. Thus, by adding the Phillips curve, the GerlachSmets model introduces an additional six parameters that require estimation $\left(\left\{\phi_{1}, \ldots, \phi_{5}\right\}\right.$ and the variance of $e_{t}$ ). The Kuttner model also allows for a non-zero correlation between $e_{t}$ and the shock to the cycle, $\eta_{t}$. Thus, it introduces eight additional parameters that require estimation $\left(\left\{\xi_{1}, \ldots, \xi_{6}\right\}\right.$, the variance of $e_{t}$ and its covariance with $\left.\eta_{t}.\right)$

\section{Data Sources and Revision Concepts}

\section{A. Data}

Most of our data is taken from the real-time data set compiled by Croushore and Stark (forthcoming); we use the quarterly real-time variables for real output from 1965:1 to 1997:4. Construction of the series and its revision over time is further described in Orphanides and van Norden (1999). We use 2000:1 data as "final data" recognizing, of course, that "final" is very much an ephemeral concept in the measurement of output. To implement the bivariate models, we also use the quarterly rate of inflation in the consumer price index (CPI) as available in 2000:1. CPI data do not generally undergo a revision process similar to that of output data. We therefore use this vintage of CPI data for all the analysis, allowing us to focus our attention on the effects of revisions in the output data.

\section{B. Measuring the revision of output gaps}

We use our data with each of the detrending methods described earlier to produce estimated output gap series. We apply each detrending method in a number of different ways in order to estimate and decompose the extent of the revisions in the estimated gap series.

The first of these estimates for each method simply takes the last available vintage of data (2000:1) and detrends it. The resulting series of deviations from trend constitutes our Final estimate of the output gap corresponding to that method.

The Real-Time estimate of the output gap is constructed in two stages. First, we detrend each and every vintage of data available to construct an ensemble of output gap series. That is, in every quarter we apply the detrending method with data as available 
during that quarter. Next, we use these different vintages to construct a new series which consists of the latest available estimate of the output gap for each point in time. The resulting Real-Time estimate represents the most timely estimate of the output gap which could be constructed in real time using the method employed.

The difference between the Real-Time and the Final estimate gives us the total revision in the estimated output gap at each point in time. This revision may have several sources, one of which is the ongoing revision of published data. To isolate the importance of this factor, we define a third output gap measure, the Quasi-Real estimate. The Quasi-Real estimate of the output gap is simply the rolling estimate based on the Final data series. That is, the gap at period $t$ is calculated using only observations 1 through $t$ to estimate the long-run trend and the deviations around it. The difference between the Real-Time and the Quasi-Real series is entirely due to the effects of data revision, since estimates in the two series at any particular point in time are based on data samples covering exactly the same period.

For unobserved component (UC) models, we further decompose the revision in the estimated gap by defining a Quasi-Final estimate. UC models use the data in two distinct phases. First, they use the available data sample to estimate the parameters of a timeseries model of output. Next, they use these estimated parameters to construct filtered and smoothed estimates of the output gap. For this class of models, smoothed estimates of the output gap are used to construct the Final series, while filtered estimates are used for the Quasi-Final series. $^{4}$

The difference between the Quasi-Final and the Quasi-Real series reflects the use of different parameter estimates (i.e. full-sample ones versus partial-sample ones) to filter the data. The extent of the difference will reflect the importance of parameter instability in the underlying UC model. The difference between the Quasi-Final and the Final series reflects the importance of ex post information in estimating the output gap given the parameter

\footnotetext{
${ }^{4}$ In both cases, the UC model's parameters are estimated using the full sample of the same data which is then used for filtering and smoothing. The sole exception is the HP filter for which no parameters are estimated.
} 
values of the process generating output. ${ }^{5}$

\section{Standard Errors and Confidence Intervals}

For the UC models, we compute standard errors and the corresponding gaussian confidence intervals for the estimates of the output gaps and revisions. The Kalman filter and smoother provide estimates of the mean-squared error associated with the Quasi-Final (filtered) and Final (smoothed) estimates of the output gap. We use these to construct $95 \%$ confidence intervals for these estimates of the gap and for their revision. The Kalman filter standard errors are appropriate for gauging the size of the Final/Quasi-Final revisions, since both estimates are conditioned on a given parameter vector. Because these standard error estimates ignore the effect of parameter uncertainty on estimation of the gap, we also employ the approximation suggested by Ansley and Kohn (1986) to compute a comparable set of confidence intervals that capture this uncertainty. We use the Ansley-Kohn errors and confidence intervals to gauge the size of the total revisions. The Ansley-Kohn standard errors approximate the uncertainty associated with the Final parameter estimates. In this respect, they are typical of the reliability calculations found previously in the output gap literature. We stress, however, that these capture neither the effects of data revision nor the presumably greater parameter uncertainty found in the shorter samples available for estimation in real time. A test statistic can also be constructed, in the spirit of Diebold and Mariano (1995), of the null hypothesis that the size of the revisions is consistent with the estimated confidence intervals. Details on these calculations may be found in the Appendix.

\section{Results}

Figure 1 compares the estimated business cycles for the eight different methods mentioned in Section 2. Real-Time estimates are shown in the top half of the figure while Final estimates are shown in the lower half. The shaded regions reflect recessions as dated by the National Bureau of Economic Research (NBER). Several features are readily apparent. The

\footnotetext{
${ }^{5}$ St-Amant and van Norden (1998) argue that the degree to which the subsequent behavior of output is informative about the output gap is linked to presence or absence of hysteresis in output.
} 
different methods have strong short-term comovements; most appear to be moving upwards or downwards at roughly the same time. Further, the different methods typically give rise to a wide range of estimates for the output gap though the range of final estimates is not as wide as the range of real-time estimates.

\section{A. Revision size and persistence}

Figure 2 shows the total revision in the output gap for each method, that is the difference between the Final and Real-Time estimates. Table 1 provides descriptive statistics on the various Real-Time, Quasi-Real, Quasi-Final and Final estimates, while Table 2 provides provides similar statistics for the total revision. Comparing the two tables, we see that the revisions are of the same order of magnitude as the estimated output gaps, although this varies somewhat across methods. The last column of Table 2 reports the estimated first order autocorrelation coefficients for the revisions. All the revision series are highly persistent, with coefficients ranging from 0.80 for the Gerlach-Smets model to 0.96 for the Quadratic Trend.

It is worth noting that the statistical properties of these revisions are broadly in line with those of the revisions of "official" output gap estimates for the United States. For example, the revisions of Federal Reserve staff estimates of the output gap for the 1980s and early 1990s reported in Orphanides (1998), have a root mean square of 2.84 percent, compared to a standard deviation of 2.44 percent for historical estimates available at the end of 1994. The autocorrelation of those revisions also exceeds $0.8 .^{6}$

Table 3 presents some measures of the relative importance of the revision in each series. Column 1 presents the correlation between the Final and Real-Time series for each method, which ranges from a low of 0.49 for the Hodrick-Prescott filter to a high of 0.89 for the Linear Trend and Watson models. The next two columns, NS and NSR, provide two proxies for

\footnotetext{
${ }^{6}$ During the 1960s and 1970s, Federal Reserve staff relied on the Council of Economic Advisers estimates of potential output to construct estimates of the output gap. As shown in Orphanides (2000), the "official" estimates for the 1960s and 1970s, produced and published by the Council of Economic Advisors and Commerce Department were subject to even greater revision errors. Of course, such comparisons should be interpreted with caution as official estimates have been based on statistical methodologies that have evolved over time - presumably reflecting changes in beliefs about how best to estimate the output gap-and also incorporate judgemental considerations that cannot be fully captured with statistical methods.
} 
the noise-to-signal ratio in the Real-Time estimates. NS (NSR) reports the ratio of the standard deviation (the root mean square) of the total revision to the standard deviation of the final estimate of the gap. NSR therefore captures the effects of persistent upward or downward revisions and exceeds one for six out of the eight methods reported. ${ }^{7}$ Even the best methods have rather large ratios by these criteria. ${ }^{8}$ The last column provides the frequency with which the Real-Time and Final gaps were of opposite signs. For five methods this frequency exceeds 40 percent and for the Kuttner and Linear Trend models, it is almost 50 percent. These results show that the errors associated with real-time estimates of the output gap are substantial. Ex post revisions are of the same order of magnitude as the ex post estimates of the gap, estimation errors appear to contain a highly persistent component of substantial size, and the real-time estimates frequently misclassify the sign of the gap.

\section{B. Decomposition of Revisions}

To help us understand the importance of different factors in accounting for the total revision for each method, in Figures 3 through 7 we plot the Real-Time estimate of the output gap together with its total subsequent revision and the components of that revision. Table 4 presents related summary statistics.

Figure 3 shows results for the Linear Trend. As a guide to subsequent figures for the other methods, we discuss this figure in some detail. First, compare the total revision to the Real-Time estimate. The fact that the revision is roughly equal to the Real-Time estimate at the trough of the 1975 recession tells us that our final estimate of the output gap is roughly zero. In other words, despite the extreme evidence of recession in the Real-Time estimate, ex post we would judge that the economy was operating roughly at potential at that time, by this method.

To understand the source of these revisions, the graph also shows the effects of data revision (measured as the Real-Time estimate minus the Quasi-Real estimate). For example,

\footnotetext{
${ }^{7}$ The NSR ratio for the Federal Reserve staff estimates mentioned earlier is 1.16.

${ }^{8}$ Using the root mean square of the output gap as the benchmark for comparison yields similar conclusions. These alternative ratios can be constructed from Tables 1 and 2 .
} 
the total revision and data revision are roughly equal in both graphs in late 1995 which means that nearly all of the revision in our estimated output gap for those quarters was due to subsequent revisions in the published data.

Looking at the whole sample period, the data revision is typically less than \pm 2 percent of output and its variability tends to be small compared to that of the total revision. This in turn means that most of the revision is due to the addition of new points to our data sample. However, data revisions still play a role as can be confirmed by looking at the summary statistics of the difference between the Quasi-Real and Real-Time estimates of the output gap shown in Table 4 .

Figures 4, 5 and 6 show results for the Breaking Trend, Quadratic Trend and HP filter models. Again we note that the total revision is often close to the size of the Real-Time output gap. Further, although the data revisions seem to play a secondary role in explaining the total revision of the Real-Time estimates, some exceptions are notable.

Figures 7 and 8 show results from the four estimated UC models. The models are paired so that each figure shows results from a univariate model (top panel) and its multivariate counterpart that incorporates information from a Phillips curve (bottom panel.) Figure 7 presents the Watson and Kuttner models. The two models provide somewhat similar real-time estimates of the gap. As with the models discussed earlier, the total revision is frequently close to the size of the Real-Time output gap and the data revision only accounts for a small part of the total. Instead, changing parameter estimates play a large role and systematically revise potential output downwards.

The revisions of the Watson and Kuttner models resemble those of the Linear Trend model seen in Figure 3. This suggests that these models' performance suffers from their common assumption of a constant long-term trend in output growth. Given the secular decline in output growth over our sample, this assumption leads to persistent downward revisions in estimates of the "constant" trend rate of growth.

Note that the addition of the Phillips curve in the Kuttner model does not enhance the reliability of the output gap estimates relative to the Watson model. The figure and 
Table 4 show that the total revision is both more biased and more variable for the Kuttner model than for the Watson model. Comparison of the standard deviation of the QuasiFinal/Quasi-Real revisions for the two models indicates that the error introduced by the estimation of the additional parameters required for the Kuttner model is substantial.

In Figure 8 we consider the results from the Harvey-Clark and Gerlach-Smets models. For the Harvey-Clark model, both parameter revision and data revision effects are relatively minor. In contrast, the Gerlach-Smets model exhibits much larger parameter revision, due in part to particularly severe parameter instability in the Quasi-Real estimates of the output gap. Again, the addition of the Phillips curve does not appear to enhance the reliability of the resulting output gap estimates.

\section{Turning Points}

It is particularly interesting to know how the different business cycle measures do around business cycle turning points, since these are presumably periods when an accurate and timely estimate of the output gap (and its changes) would be of particular interest to policy makers. To help assess this, we calculated a number of descriptive statistics regarding the size or the revision in Real-Time estimates in the three quarters centered about each of the NBER business cycle peaks from 1966 to 1997. Results are shown in Table 5. We see that all methods seem to underestimate the output gap in Real-Time at cyclical peaks, although the degree to which this is true varies considerably from one method to another. The Linear Trend, Watson and Kuttner methods have the most severe underestimates while all but the Breaking Trend underestimate the gap by more than $1.5 \%$ on average.

\section{Revisions and Confidence Intervals}

Figures 9 and 10 present the output gap estimates and their confidence intervals from the four estimated UC models. The top and middle panels show Quasi-Final and Final estimates of the output gap with their corresponding $95 \%$ confidence intervals. The bottom panel shows the Final/Quasi-Final and total (Final/Real-Time) revisions together with two sets

of confidence intervals, which alternatively ignore (Kalman) and include (Ansley-Kohn) the 
estimated effects of parameter uncertainty.

Comparing confidence intervals for the Harvey-Clark and Gerlach-Smets models in Figure 9, we see that the Kalman bands are somewhat narrower for the Gerlach-Smets model but the Ansley-Kohn bands are considerably wider, on average. ${ }^{9}$ This suggests that, in the absence of parameter uncertainty, incorporating information from the Phillips curve based on the final data helps narrow the uncertainty of the estimated output gaps. However this narrowing is reversed when parameter uncertainty is accounted for.

Perhaps more importantly, both sets of confidence bands include zero in virtually every quarter from 1966 to 1997. This is true for both the Final and Quasi-Final gaps and for both models. Thus, these gap estimates are virtually never significantly different from zero in this sample. The situation must be worse for Real-Time estimates, since these face additional effects of parameter uncertainty and data revision not accounted for in these bands.

Examining the revisions in the bottom panel suggests that neither the Final/QuasiFinal nor the total revisions appear unusually large relative to their confidence intervals. This impression is confirmed by the results in Table 6. The first two columns give the RMS revisions (Final-RealTime, from Table 2) and the mean of the Ansley-Kohn standard errors for the revisions. The third column reports the test statistic for the null hypothesis that these revisions are consistent with these standard errors. The statistic is approximately normally distributed so that rejection against the one-sided alternative that the revisions are larger than expected requires large positive values. For the Harvey-Clark and the GerlachSmets models, it shows no significant evidence that the revisions are larger than one should expect.

Figure 10 presents the corresponding estimates and confidence bands for the Watson and Kuttner models. ${ }^{10}$ The gaps for the Watson model are (with only few exceptions) not significantly different from zero. The Kuttner model gives much more evidence of significant

\footnotetext{
${ }^{9}$ For the 1966:1 to 1997:4 period shown in the figure, the average Kalman standard errors for the QuasiFinal estimates from the Harvey-Clark and Gerlach-Smets models are 2.32 and 1.93 percent, respectively. By contrast, the corresponding average Ansley-Kohn standard errors are 2.46 and 8.78 percent.

${ }^{10}$ The average Kalman (Ansley-Kohn) standard errors for the QuasiFinal estimates from the Watson and Kuttner models are 1.81 (2.42) and 1.83 (2.20) percent, respectively.
} 
output gaps, including, perhaps surprisingly, most of the first half of the 1990s.

The Final/Quasi-Final revision falls within the Kalman bands in virtually every quarter for both models. However, the total revisions are frequently outside the Ansley-Kohn bands. This is reflected by the test statistics in Table 6, which strongly reject the null in favour of the alternative that total revisions are more volatile than these standard errors predict. ${ }^{11}$ This suggests that the calculated confidence intervals understate the degree of uncertainty associated with real-time estimates of the output gap for these two models.

Finally, we note that for policy simulation exercises, it would be helpful to know the magnitude of the total estimation error associated with typical RealTime estimates of the output gap. For the Kuttner and Watson models, the results presented in Table 6 imply that the average mean square errors estimated for the QuasiFinal (i.e. filtered) estimates of the UC models significantly underestimate the true degree of uncertainty in RealTime estimates. The Gerlach-Smets estimates suggest severe effects of parameter uncertainty in that model. For the Harvey-Clark model, the average Ansley-Kohn standard error of the QuasiFinal estimates is 1.6 (1.1) times the standard deviation of its Quasi-Final (Final) output gap estimates. These error estimates may appear to be rather large. However, based on the models we have examined, it appears unrealistic to assume significantly better accuracy than this in policy simulations.

\section{Conclusions}

We have examined the reliability of several detrending methods for estimating the output gap in real time. In doing so, we have focused on the extent to which output gap estimates are updated over time as more information arrives and data are revised. This gives us results which are robust to alternative assumptions about the structure of the economy and give lower bounds on the estimation error associated with any given method.

Our results suggest that the reliability of output gap estimates in real time tends to be quite low. The revisions are of the same order of magnitude as the estimated output gap

\footnotetext{
${ }^{11}$ The same was not true for test statistics (not reported) using Final/Quasi-Final revisions and Kalman standard errors.
} 
itself for all the methods examined. The size of the measurement error is compounded by a high degree of persistence of the revisions. While these results are based on a mechanical application of simple models, they mirror results based on the revision of output gap series produced by the Federal Reserve staff during the 1980s and early 1990s.

For unobserved component models, we find that multivariate methods that incorporate information from inflation to estimate the output gap are not more reliable than their univariate counterparts. Though the information from multivariate methods may be useful in principle, their added complexity introduces additional sources of parameter uncertainty and instability which may offset the potential improvement in real time.

Although important, the revision of published data does not appear to be the primary source of revisions for the methods we examined. Rather, the bulk of the problem is due to the pervasive unreliability of end-of-sample estimates of the output trend. Thus, even if the reliability of the underlying real-time data were to improve, real-time estimates of the output gap would remain unreliable.

Our findings suggest that output gap mismeasurement may pose a serious policy problem, one that can be especially acute for economic stabilization policy. Policy experiments in macroeconometric models suggest that a strong systematic policy response to the output gap could greatly stabilize economic fluctuations - provided a reliable measure of the output gap is available for policymakers to use. ${ }^{12}$ However, policy actions based on incorrect measures of the output gap can inadvertently cause instability. Policy design based on the erroneous presumption of unwarranted reliability can lead to flawed policy recommendations. ${ }^{13}$ In light of the unreliability of real-time estimates of the output gap, great caution is required in their use.

\footnotetext{
${ }^{12}$ See, for example, Taylor (1999) for a recent survey of policy evaluations of this nature.

${ }^{13} \mathrm{An}$ informative illustration of this pitfall in the context of Linear-Quadratic-Gaussian (LQG) models of optimal control is provided in Orphanides (1998).
} 


\section{References}

Ansley C. F. and R. Kohn, "Prediction mean square error for state space models with estimated parameters," Biometrika, 73 (1986), 467-74.

Clark, Peter K., "The Cyclical Component of U.S. Economic Activity," Quarterly Journal of Economics 102(4) (1987), 797-814.

Council of Economic Advisers, Economic Report of the President, (Washington, D.C.: U.S. Printing Office, 1977).

Croushore, Dean and Tom Stark, "A Real-Time Data Set for Macroeconomists," Journal of Econometrics, (forthcoming).

Diebold, Francis X. and Roberto S. Mariano, "Comparing Predictive Accuracy," Journal of Business and Economic Statistics, 13 (1995), 253-265.

Gerlach, Stefan and Frank Smets, "Output Gaps and Inflation: Unobserable-Components Estimates for the G-7 Countries." Bank for International Settlements mimeo, Basel (1997)

Hamilton, James, "A Standard Error for the Estimated State Vector of a State-Space Model," Journal of Econometrics, 33 (1986), 387-97.

Hamilton, James, Time Series Analysis, (Princeton University Press, 1994).

Harvey, Andrew C., "Trends and Cycles in Macroeconomic Time Series," Journal of Business and Economic Statistics, 3 (1985). 216-227.

Harvey, Andrew C., Forecasting, Structural Time Series Models and the Kalman Filter, (Cambridge University Press, 1989).

Harvey, A. C. and A. Jaeger, "Detrending, Stylized Facts, and the Business Cycle," Journal of Applied Econometrics, 8 (1993), 231-247.

Henderson, R. "A New Method of Graduation." Actuarial Society of America Transactions, 25 (1924), 29-40.

Hodrick, R, and E. Prescott, "Post-war Business Cycles: An Empirical Investigation," Journal of Money, Credit, and Banking, 29 (1997), 1-16.

King, Robert G. and Sergio Rebelo (1993), "Low Frequency Filtering and Real Business Cycles." Journal of Economic Dynamics and Control, 17(1-2), 207-31.

Kuttner, Kenneth N., "Monetary Policy with Uncertain Estimates of Potential Output," Economic Perspectives, Federal Reserve Bank of Chicago, 16 (1992), 2-15.

Kuttner, Kenneth N., "Estimating Potential Output as a Latent Variable," Journal of Business and Economic Statistics, 12(3) (1994), 361-68.

McCallum, Bennett and Edward Nelson, "Performance of Operational Policy Rules in An 
Estimated Semi-Classical Structural Model," in Taylor, John, ed. Monetary Policy Rules, (Chicago: University of Chicago Press, 1999).

Orphanides, Athanasios, "Monetary Policy Evaluation With Noisy Information," Finance and Economics Discussion Series, 1998-50, Federal Reserve Board, (October 1998).

Orphanides, Athanasios, "The Quest for Prosperity Without Inflation," Working Paper No. 15, European Central Bank, (March 2000).

Orphanides, Athanasios, "Monetary Policy Rules Based on Real-Time Data," American Economic Review, (September 2001).

Orphanides, Athanasios and Simon van Norden, "The Reliability of Output Gap Estimates in Real Time," Finance and Economics Discussion Series 1999-38, Federal Reserve Board, (August 1999).

Persons, Warren M., "Indices of Business Conditions," The Review of Economic Statistics 1(1), 5-107, (January 1919).

Pfeffermann, Danny and Richard Tiller, "Bootstrap Approximation to Prediction MSE for State-Space Models with Estimated Parameters," Manuscript (2000).

Quenneville, B., and Singh, A. C., "Bayesian Prediction Mean Square Error for State Space Models with Estimated Parameters," Journal of Time Series Analysis, 21 (2000), 219236.

Smets, Frank, "Output Gap Uncertainty: Does it Matter for the Taylor Rule?" BIS Working Paper No. 60, (November 1998).

St-Amant, Pierre and Simon van Norden (1998), "Measurement of the Output Gap: A discussion of recent research at the Bank of Canada," Bank of Canada Technical Report No. 79 (1998).

Staiger, Douglas, James H. Stock, and Mark W. Watson, "How Precise are Estimates of the Natural Rate of Unemployment?" in Romer, Christina and David Romer, eds. Reducing Inflation: Motivation and Strategy, (Chicago: University of Chicago Press, 1997a).

Staiger, Douglas, James H. Stock, and Mark W. Watson, "The NAIRU, Unemployment and Monetary Policy," Journal of Economic Perspectives 11(1) (Winter 1997), 33-49.

Taylor, John B., "The Robustness and Efficiency of Monetary Policy Rules as Guidelines for Interest Rate Setting by the European Central Bank," Journal of Monetary Economics, 43(3) (June 1999), 655-79.

Watson, Mark W., "Univariate Detrending Methods with Stochastic Trends," Journal of Monetary Economics, 18 (1986), 49-75.

Whittaker, E. T., "On a New Method of Graduation." Proceedings of the Edinburgh Mathematical Society, 41 (1923), 63-75. 


\section{Appendix: Confidence Intervals for UC Models}

\section{A.1 Revisions}

Let $S_{t \mid \tau}$ denote the estimate of the unobserved state vector $S_{t}$ conditional on the parameter vector $\theta$ of the UC model as well as on all data available through time $\tau$. Since we do not observe $\theta$, we replace it by its maximum likelihood estimator $\hat{\theta}$. For convenience, we will refer to $S_{t \mid t}(\hat{\theta})$ as the "filtered" estimate $S_{t \mid t}$ and to $S_{t \mid T}(\hat{\theta})$ as the "smoothed" estimate $S_{t \mid T}$. For a given $\hat{\theta}$, the revision in this estimate may be defined as $R_{t \mid T}=S_{t \mid T}-S_{t \mid t} .{ }^{14}$

If we have $P_{t \mid t}=\operatorname{Var}\left(S_{t \mid t}-S_{t}\right)$ and $P_{t \mid T}=\operatorname{Var}\left(S_{t \mid T}-S_{t}\right)$, then it follows that

$$
\begin{array}{r}
P_{t \mid t}=\operatorname{Var}\left(S_{t \mid t}-S_{t}\right)=\operatorname{Var}\left(\left(S_{t \mid t}-S_{t \mid T}\right)+\left(S_{t \mid T}-S_{t}\right)\right), \\
P_{t \mid t}=\operatorname{Var}\left(R_{t \mid T}\right)+P_{t \mid T}+\operatorname{Cov}\left(S_{t \mid t}-S_{t \mid T}, S_{t \mid T}-S_{t}\right)
\end{array}
$$

Provided this last term is zero, the variance of the revision must be

$$
\operatorname{Var}\left(R_{t \mid T}\right)=P_{t \mid t}-P_{t \mid T}
$$

$S_{t \mid t}-S_{t \mid T}$ will be orthogonal to $S_{t \mid T}-S_{t}$ since $S_{t \mid T}$ incorporates all information available up to time $T .{ }^{15}$ In what follows, we use equation (A.2) as the basis of our calculations for the confidence intervals surrounding revisions $R_{t \mid T}$.

\section{A.2 Standard Errors}

If $\theta$ is known, $P_{t \mid t}(\theta)$ and $P_{t \mid T}(\theta)$ may be calculated using the usual Kalman Filter equations. In reality, however, we have only $\hat{\theta}$, and its estimation uncertainty therefore adds to the uncertainty in our estimated output gaps. We therefore require estimates of $P_{t \mid t}(\hat{\theta})>P_{t \mid t}(\theta)$ and $P_{t \mid T}(\hat{\theta})>P_{t \mid T}(\theta)$.

Hamilton (1986) suggests a Bayesian simulation approach to the problem. It draws $n$ i.i.d. parameter vectors $\theta_{i}$ from a multivariate normal distribution $N\left(\hat{\theta}, \hat{\Sigma}_{\theta}\right),{ }^{16}$ then uses the simulated values of $\frac{1}{n} \sum_{i=1}^{n}\left(S_{t \mid t}(\hat{\theta})-S_{t \mid t}\left(\theta_{i}\right)\right)^{2}$ and $\frac{1}{n} \sum_{i=1}^{n}\left(S_{t \mid T}(\hat{\theta})-S_{t \mid T}\left(\theta_{i}\right)\right)^{2}$ as estimates of $P_{t \mid t}(\hat{\theta})-P_{t \mid t}(\theta)$ and $P_{t \mid T}(\hat{\theta})-P_{t \mid T}(\theta) .{ }^{17}$ Alternatively, Ansley and Kohn (1986) suggest using the first-order approximation: ${ }^{18}$

$$
\begin{gathered}
P_{t \mid t}(\hat{\theta})-P_{t \mid t}(\theta)=\left(\left.\frac{d}{d \theta} S_{t \mid t}(\theta)\right|_{\theta=\hat{\theta}}\right) \hat{\Sigma}_{\theta}\left(\left.\frac{d}{d \theta} S_{t \mid t}(\theta)\right|_{\theta=\hat{\theta}}\right)^{\prime} \\
P_{t \mid T}(\hat{\theta})-P_{t \mid T}(\theta)=\left(\left.\frac{d}{d \theta} S_{t \mid T}(\theta)\right|_{\theta=\hat{\theta}}\right) \hat{\Sigma}_{\theta}\left(\left.\frac{d}{d \theta} S_{t \mid T}(\theta)\right|_{\theta=\hat{\theta}}\right)^{\prime}
\end{gathered}
$$

\footnotetext{
${ }^{14}$ If $\hat{\theta}$ is fixed at its full-sample (Final) estimate, this corresponds to the revision from the Quasi-Final to the Final estimate of the state vector.

${ }^{15}$ More generally, this would continue to hold if we replace $S_{t \mid t}(\hat{\theta})$ with $S_{t \mid t}(\theta)$ and $S_{t \mid T}(\hat{\theta})$ with $S_{t \mid T}(\theta)$ for any arbitrary $\theta$.

${ }^{16} \hat{\Sigma}_{\theta}$ is simply the estimated variance-covariance matrix of $\hat{\theta}$ about its true value $\theta$.

${ }^{17}$ See Hamilton (1994), section 13.7, p. 397-399, for a more detailed exposition.

${ }^{18}$ See Harvey (1989) p. 149. These derivatives are typically not available in closed form but may be easily computed numerically.
} 
Quenneville and Singh (2000) stress that both of these methods are simply approximations, but their simulations suggest that the Ansley and Kohn approach performs better in small samples. ${ }^{19}$ We experimented with both methods but found the Hamilton approach problematic in our case. For some parameter draws with some models, the output gap became explosive, generating extremely large standard errors or numeric overflows. For these reasons, the results we report are based exclusively on the Ansley-Kohn method.

As noted in (A.2), the implied variability of $R_{t \mid T}$ is simply the difference of the variances of the filtered and smoothed estimates. When $\theta$ is known, the Kalman filter guarantees that this difference is always positive semi-definite. The same cannot be said of the approximations above for $P_{t \mid t}(\hat{\theta})$ and $P_{t \mid T}(\hat{\theta})$; neither Hamilton's nor Ansley and Kohn's method guarantees $P_{t \mid t}(\hat{\theta})>P_{t \mid T}(\hat{\theta}) .{ }^{20}$ However, a logical extension which guarantees this result is to simply use

$$
\begin{array}{r}
\operatorname{Var}\left(R_{t \mid T}\right)=\left(P_{t \mid t}(\theta)-P_{t \mid T}(\theta)\right)+ \\
\left.\left.\frac{d}{d \theta}\left(S_{t \mid T}(\theta)-S_{t \mid t}(\theta)\right)\right|_{\theta=\hat{\theta}} \hat{\Sigma}_{\theta} \frac{d}{d \theta}\left(S_{t \mid T}(\theta)-S_{t \mid t}(\theta)\right)^{\prime}\right|_{\theta=\hat{\theta}}
\end{array}
$$

Accordingly, (A.4) is used to generate the implied confidence intervals for the revisions under the null hypothesis that $R_{t \mid T} \sim N\left(0, \operatorname{Var}\left(R_{t \mid T}\right)\right)$.

\section{A.3 Test Statistics}

Equation (A.4) allows us to construct a confidence interval for the revision at any specific point in time. We also wish to test whether the variability of $R_{t \mid T}$ over the entire observed sample is consistent with what we would expect from our UC model and its parameter estimates. One way to test this would be to standardize the revisions by their estimated standard errors $\sigma_{t \mid T}=\sqrt{\operatorname{Var}\left(R_{t \mid T}\right)}$ and test the variance of the resulting process. A problem here is that $R_{t \mid T}$ is almost certain to be serially correlated. We correct for this using a heteroscedasticity and autocorrelation consistent (HAC) estimator along the same lines as Diebold and Mariano (1995). Specifically, we construct the test statistic

$$
D=\left(\frac{1}{T} \sum_{t=1}^{T}\left(R_{t \mid T} / \sigma_{t \mid T}\right)^{2}-1\right) \omega^{-1}
$$

which has an asymptotic standard normal distribution under the null hypothesis that $E\left(R_{t \mid T}\right)=0$ and $E\left(R_{t \mid T}^{2}\right)=\sigma_{t \mid T}^{2}$. Here, $\omega$ is a HAC estimate of the standard deviation of $\left(R_{t \mid T} / \sigma_{t \mid T}\right)^{2}$. Approximate p-values for $D$ were simply calculated using the standard normal cdf. For the results reported in Table 6, we computed the statistic using 8 lags and a Bartlett kernel. We found similar results using a Parzen kernel and using lag truncation parameters from 5 to 10 .

\footnotetext{
${ }^{19}$ Quenneville and Singh (2000) and Pfeffermann and Tiller (2000) both suggest more sophisticated approximations. However, the former's simulations show that their method works only about as well as Ansley and Kohn's, while the latter method is too computationally intensive to be practical in our context.

${ }^{20}$ In practice, this proved to be a problem for both methods, although the problem was more common for the Hamilton method.
} 
Table 1

Output Gap Summary Statistics

\begin{tabular}{lccccc}
\hline \hline Method & MEAN & SD & MIN & MAX & COR \\
\hline \hline Hodrick-Prescott & & & & & \\
\hline Final & 0.04 & 1.65 & -4.67 & 3.60 & 1.00 \\
Quasi-Real & -0.12 & 1.70 & -3.96 & 3.79 & 0.55 \\
Real-Time & -0.27 & 1.90 & -6.63 & 3.84 & 0.49 \\
\hline Breaking Trend & & & & & \\
\hline Final & 0.18 & 2.58 & -6.98 & 5.31 & 1.00 \\
Quasi-Real & 0.56 & 2.79 & -6.55 & 7.02 & 0.85 \\
Real-Time & 0.21 & 3.15 & -10.52 & 5.02 & 0.82 \\
\hline Quadratic Trend & & & & & \\
\hline Final & 0.30 & 2.72 & -7.39 & 5.20 & 1.00 \\
Quasi-Real & -0.70 & 2.71 & -7.23 & 6.19 & 0.60 \\
Real-Time & -0.96 & 3.03 & -10.83 & 4.70 & 0.58 \\
\hline Linear Trend & & & & & \\
\hline Final & 1.30 & 3.87 & -5.44 & 8.06 & 1.00 \\
Quasi-Real & -2.65 & 3.49 & -10.32 & 7.02 & 0.88 \\
Real-Time & -3.45 & 3.98 & -10.52 & 5.02 & 0.89 \\
\hline Watson & & & & & \\
\hline Final & 0.45 & 2.37 & -5.34 & 4.56 & 1.00 \\
Quasi-Final & -0.26 & 2.19 & -5.07 & 5.06 & 0.95 \\
Quasi-Real & -1.71 & 2.37 & -7.31 & 4.42 & 0.83 \\
Real-Time & -2.08 & 2.61 & -7.43 & 3.56 & 0.89 \\
\hline Kuttner & & & & & \\
\hline Final & 0.78 & 3.51 & -5.61 & 6.92 & 0.99 \\
Quasi-Final & -1.63 & 2.79 & -6.81 & 6.23 & 0.87 \\
Quasi-Real & & & & \\
Real-Time & & & & & \\
\hline \hline
\end{tabular}

(continued on next page) 
Table 1 (continued)

\section{Output Gap Summary Statistics}

\begin{tabular}{lrrrrr}
\hline \hline Method & MEAN & SD & MIN & MAX & COR \\
\hline \hline Harvey-Clark & & & & & \\
\hline Final & 0.25 & 2.17 & -5.51 & 4.06 & 1.00 \\
Quasi-Final & -0.71 & 1.53 & -4.62 & 3.21 & 0.89 \\
Quasi-Real & -0.66 & 1.60 & -4.14 & 3.41 & 0.81 \\
Real-Time & -0.93 & 1.91 & -6.99 & 3.02 & 0.77 \\
\hline Gerlach-Smets & & & & & \\
\hline Final & 0.08 & 1.95 & -5.37 & 3.51 & 1.00 \\
Quasi-Final & -0.57 & 1.55 & -4.85 & 3.30 & 0.92 \\
Quasi-Real & -0.89 & 2.57 & -13.17 & 1.95 & 0.56 \\
Real-Time & -1.57 & 2.08 & -11.05 & 0.90 & 0.75 \\
\hline \hline
\end{tabular}

Notes: The alternative detrending methods are as described in the text. The statistics shown for each variable are: MEAN, the mean; SD, the standard deviation; and MIN and MAX, the minimum and maximum values. COR, denotes the correlation with the final estimate of the gap for that method. All statistics are for the 1966:1-1997:4 period. 
Table 2

\section{Summary Revision Statistics}

Final vs Real-Time Estimates

\begin{tabular}{lrrrrrr}
\hline \hline Method & MEAN & SD & RMS & MIN & MAX & AR \\
\hline \hline Hodrick-Prescott & 0.30 & 1.81 & 1.83 & -3.48 & 3.44 & 0.93 \\
Breaking Trend & -0.04 & 1.78 & 1.78 & -5.24 & 5.93 & 0.85 \\
Quadratic Trend & 1.25 & 2.64 & 2.91 & -4.20 & 7.65 & 0.96 \\
Linear Trend & 4.78 & 1.82 & 5.12 & 0.09 & 10.21 & 0.91 \\
Watson & 2.53 & 1.17 & 2.78 & -0.11 & 5.18 & 0.89 \\
Kuttner & 3.57 & 1.75 & 3.97 & -0.83 & 7.29 & 0.92 \\
Harvey-Clark & 1.17 & 1.39 & 1.82 & -2.07 & 4.25 & 0.92 \\
Gerlach-Smets & 1.64 & 1.43 & 2.17 & -1.42 & 6.33 & 0.80 \\
\hline \hline
\end{tabular}

Notes: The detrending method and statistics are as described in the notes to Table 1. RMS denotes the root mean square of the revision series shown and AR the first order serial correlation of the series. 
Table 3

\section{Summary Reliability Indicators}

\begin{tabular}{lcccc}
\hline \hline Method & COR & NS & NSR & OPSIGN \\
\hline \hline Hodrick-Prescott & 0.49 & 1.10 & 1.11 & 0.41 \\
Breaking Trend & 0.82 & 0.69 & 0.69 & 0.22 \\
Quadratic Trend & 0.58 & 0.97 & 1.07 & 0.35 \\
Linear Trend & 0.89 & 0.47 & 1.32 & 0.49 \\
Watson & 0.89 & 0.49 & 1.17 & 0.42 \\
Kuttner & 0.88 & 0.48 & 1.09 & 0.49 \\
Harvey-Clark & 0.77 & 0.64 & 0.84 & 0.34 \\
Gerlach-Smets & 0.75 & 0.73 & 1.11 & 0.41 \\
\hline \hline
\end{tabular}

Notes: The table shows measures evaluating the size, sign and variability of the revisions for alternative methods. COR, denotes the correlation of the real-time and final estimates (from Table 1). NS indicates the ratio of the standard deviation of the revision and the standard deviation of the final estimate of the gap. NSR indicates the ratio of the root mean square of the revision and the standard deviation of the final estimate of the gap. OPSIGN indicates the frequency with which the real-time and final gap estimates have opposite signs. 
Table 4

\section{Detailed Breakdown of Revision Statistics}

\begin{tabular}{|c|c|c|c|c|c|c|}
\hline Method & MEAN & $\mathrm{SD}$ & RMS & MIN & MAX & $\mathrm{AR}$ \\
\hline \multicolumn{7}{|l|}{ Hodrick-Prescott } \\
\hline Final/Real-Time & 0.30 & 1.81 & 1.83 & -3.48 & 3.44 & 0.93 \\
\hline Final/Quasi-Real & 0.16 & 1.59 & 1.60 & -3.49 & 3.12 & 0.97 \\
\hline Quasi-Real/Real-Time & 0.14 & 0.65 & 0.66 & -1.05 & 2.95 & 0.66 \\
\hline \multicolumn{7}{|l|}{ Breaking Trend } \\
\hline Final/Real-Time & -0.04 & 1.78 & 1.78 & -5.24 & 5.93 & 0.85 \\
\hline Final/Quasi-Real & -0.38 & 1.47 & 1.51 & -3.96 & 1.99 & 0.92 \\
\hline Quasi-Real/Real-Time & 0.34 & 1.05 & 1.10 & -2.30 & 4.14 & 0.76 \\
\hline \multicolumn{7}{|l|}{ Quadratic Trend } \\
\hline Final/Real-Time & 1.25 & 2.64 & 2.91 & -4.20 & 7.65 & 0.96 \\
\hline Final/Quasi-Real & 1.00 & 2.44 & 2.63 & -1.80 & 5.27 & 0.99 \\
\hline Quasi-Real/Real-Time & 0.23 & 1.04 & 1.06 & -2.57 & 4.08 & 0.76 \\
\hline \multicolumn{7}{|l|}{ Linear Trend } \\
\hline Final/Real-Time & 4.78 & 1.82 & 5.12 & 0.09 & 10.21 & 0.91 \\
\hline Final/Quasi-Real & 3.95 & 1.81 & 4.34 & 0.07 & 6.43 & 0.96 \\
\hline Quasi-Real/Real-Time & 0.80 & 1.21 & 1.44 & -1.67 & 4.14 & 0.79 \\
\hline \multicolumn{7}{|l|}{ Watson } \\
\hline Final/Real-Time & 2.53 & 1.17 & 2.78 & -0.11 & 5.18 & 0.89 \\
\hline Final/Quasi-Final & 0.71 & 0.75 & 1.03 & -0.68 & 2.17 & 0.94 \\
\hline Quasi-Final/Quasi-Real & 1.45 & 0.85 & 1.68 & -0.23 & 2.62 & 0.95 \\
\hline Quasi-Real/Real-Time & 0.37 & 1.13 & 1.19 & -1.96 & 3.54 & 0.86 \\
\hline \multicolumn{7}{|l|}{ Kuttner } \\
\hline Final/Real-Time & 3.57 & 1.75 & 3.97 & -0.83 & 7.29 & 0.92 \\
\hline Final/Quasi-Final & 0.42 & 0.43 & 0.60 & -0.63 & 1.29 & 0.91 \\
\hline Quasi-Final/Quasi-Real & 2.40 & 1.49 & 2.82 & -0.39 & 4.86 & 0.97 \\
\hline Quasi-Real/Real-Time & 0.74 & 0.86 & 1.14 & -1.06 & 3.45 & 0.83 \\
\hline \multicolumn{7}{|l|}{ Harvey-Clark } \\
\hline Final/Real-Time & 1.17 & 1.39 & 1.82 & -2.07 & 4.25 & 0.92 \\
\hline Final/Quasi-Final & 0.96 & 1.08 & 1.44 & -1.06 & 3.23 & 0.94 \\
\hline Quasi-Final/Quasi-Real & -0.05 & 0.37 & 0.37 & -1.08 & 0.93 & 0.91 \\
\hline Quasi-Real/Real-Time & 0.27 & 0.61 & 0.66 & -0.81 & 2.85 & 0.84 \\
\hline \multicolumn{7}{|l|}{ Gerlach-Smets } \\
\hline Final/Real-Time & 1.64 & 1.43 & 2.17 & -1.42 & 6.33 & 0.80 \\
\hline Final/Quasi-Final & 0.65 & 0.79 & 1.02 & -0.88 & 2.57 & 0.93 \\
\hline Quasi-Final/Quasi-Real & 0.32 & 2.08 & 2.09 & -3.48 & 8.73 & 0.69 \\
\hline Quasi-Real/Real-Time & 0.68 & 1.94 & 2.05 & -7.88 & 5.67 & 0.61 \\
\hline
\end{tabular}

Notes: See notes to Tables 1 and 2. 
Table 5

\section{Revision Statistics at NBER Peaks \\ Final vs Real-Time Estimates}

\begin{tabular}{lrrrrr}
\hline \hline Method & MEAN & \multicolumn{1}{c}{ SD } & RMS & MIN & MAX \\
\hline \hline Hodrick-Prescott & 2.38 & 0.76 & 2.49 & 0.64 & 3.44 \\
Breaking Trend & 0.67 & 0.55 & 0.86 & -0.27 & 1.35 \\
Quadratic Trend & 2.86 & 2.07 & 3.48 & -0.95 & 5.20 \\
Linear Trend & 5.40 & 1.38 & 5.56 & 3.57 & 7.50 \\
Watson & 2.83 & 1.25 & 3.08 & 1.19 & 4.86 \\
Kuttner & 4.37 & 1.29 & 4.55 & 2.11 & 6.58 \\
Harvey-Clark & 1.82 & 0.97 & 2.04 & 0.42 & 3.80 \\
Gerlach-Smets & 1.82 & 0.84 & 1.99 & 0.47 & 3.06 \\
\hline \hline
\end{tabular}

Notes: The revision is defined as the difference between the final and the real-time estimates. For each method, the sample used to compute the revision statistics is limited to the three quarters centered around each of the NBER peaks from 1966 to 1997. See also notes to Tables 1 and 2 . 
Table 6

Standard Errors and Test for Total Revisions

\begin{tabular}{lccc}
\hline \hline Method & $\begin{array}{c}\text { Revision } \\
\text { RMS }\end{array}$ & $\begin{array}{c}\text { Mean SE } \\
\text { Ansley-Kohn }\end{array}$ & $\begin{array}{c}\text { Revision Size } \\
\text { Test Statistic }\end{array}$ \\
\hline \hline Watson & 2.79 & 1.88 & $2.84^{*}$ \\
Kuttner & 3.98 & 1.32 & $3.23^{*}$ \\
Harvey-Clark & 1.82 & 1.75 & 0.07 \\
Gerlach-Smets & 2.18 & 3.20 & -1.25 \\
\hline \hline
\end{tabular}

Notes: The root mean square (RMS) of the total revisions is from Table 2. The mean standard error (SE) and test statistic are computed for the 1966:1-1997:4 period as detailed in the Appendix. The test statistic is for the hypothesis that the size of the revisions is consistent with the estimated standard errors against the alternative that they are bigger, on average. ${ }^{*}$ indicates rejection at the $0.1 \%$ significance level. 
Figure 1

\section{Real-Time Estimates of the Business Cycle}

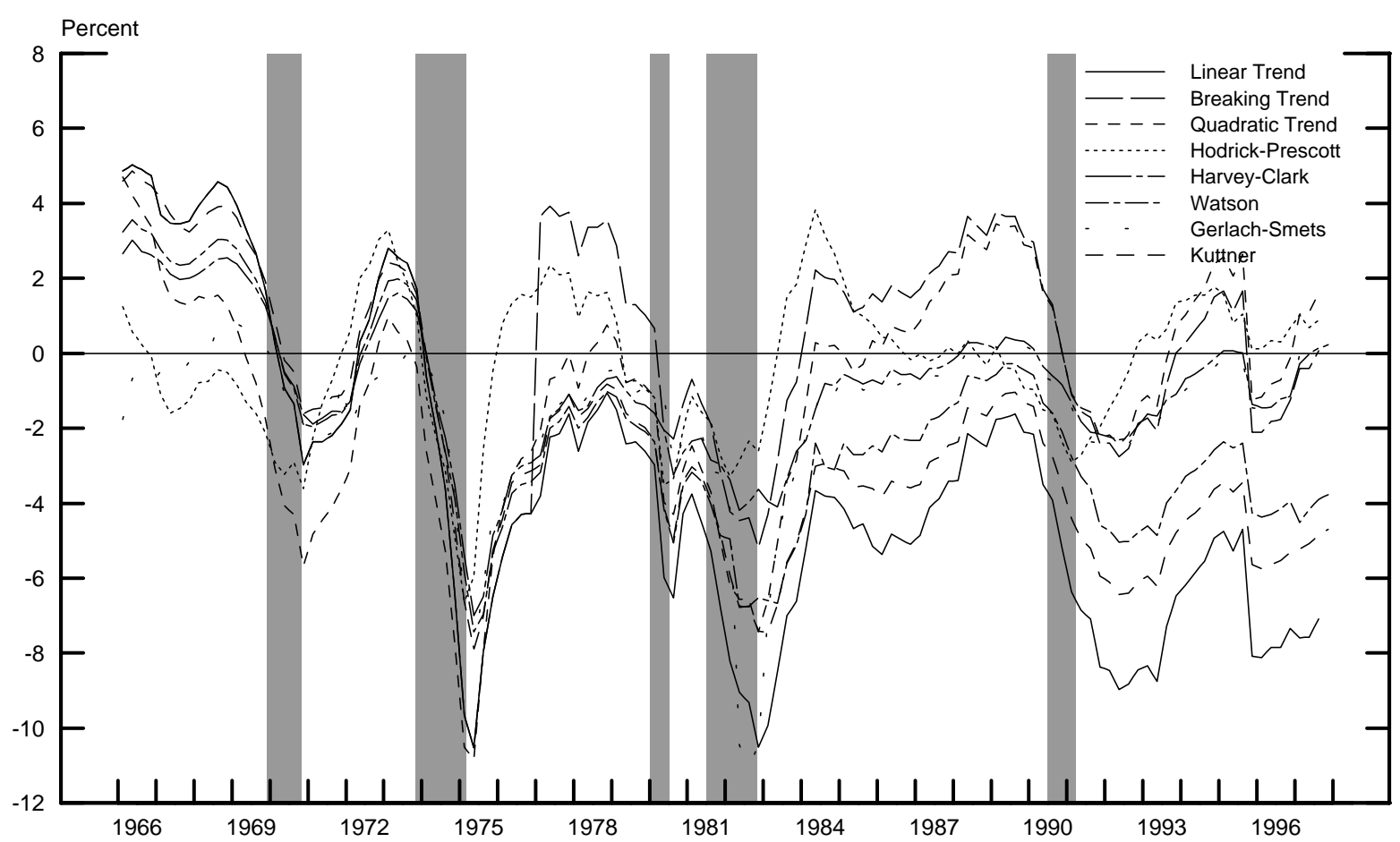

Final Estimates of the Business Cycle

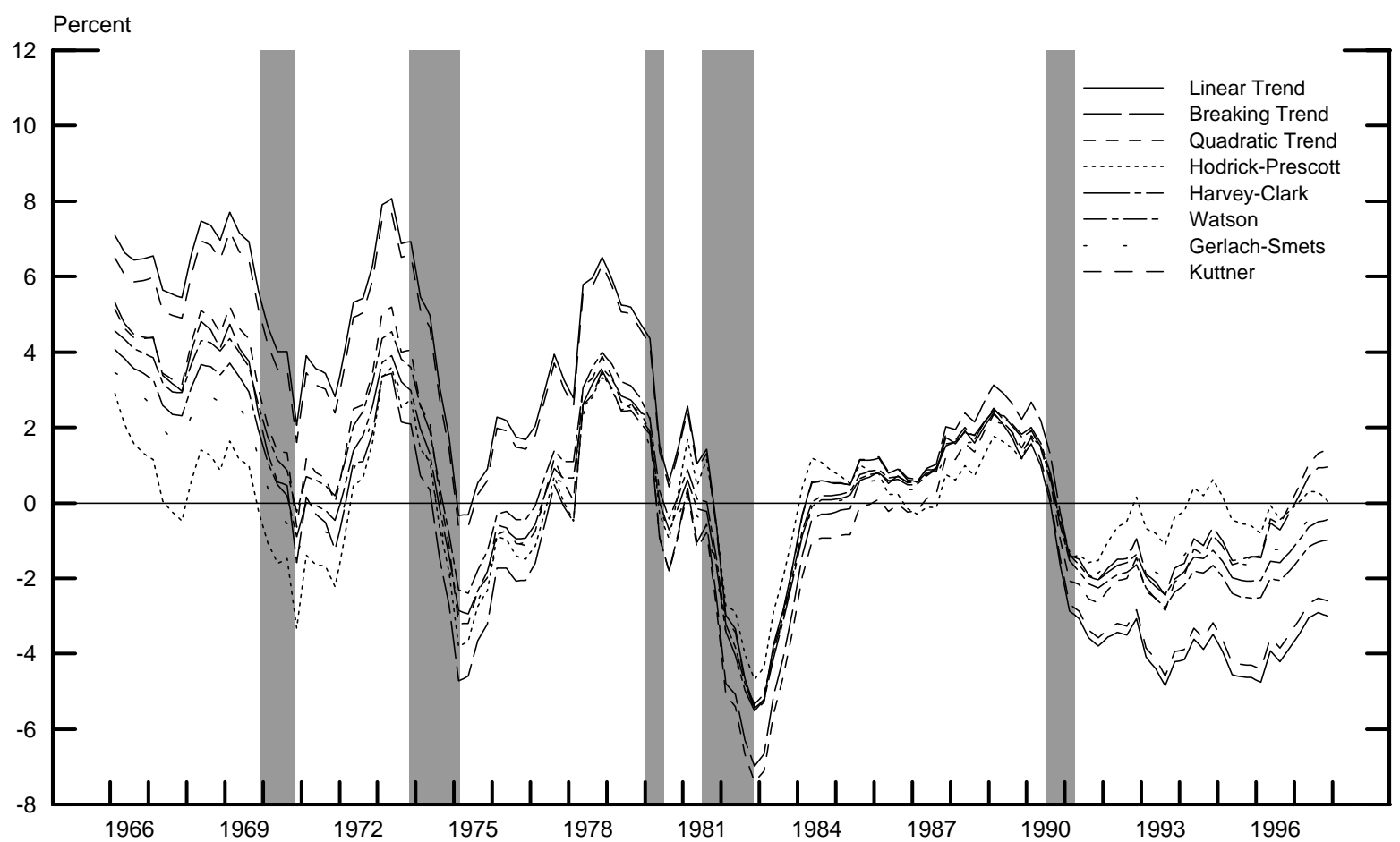


Figure 2

Total Revision in Business Cycle Estimates

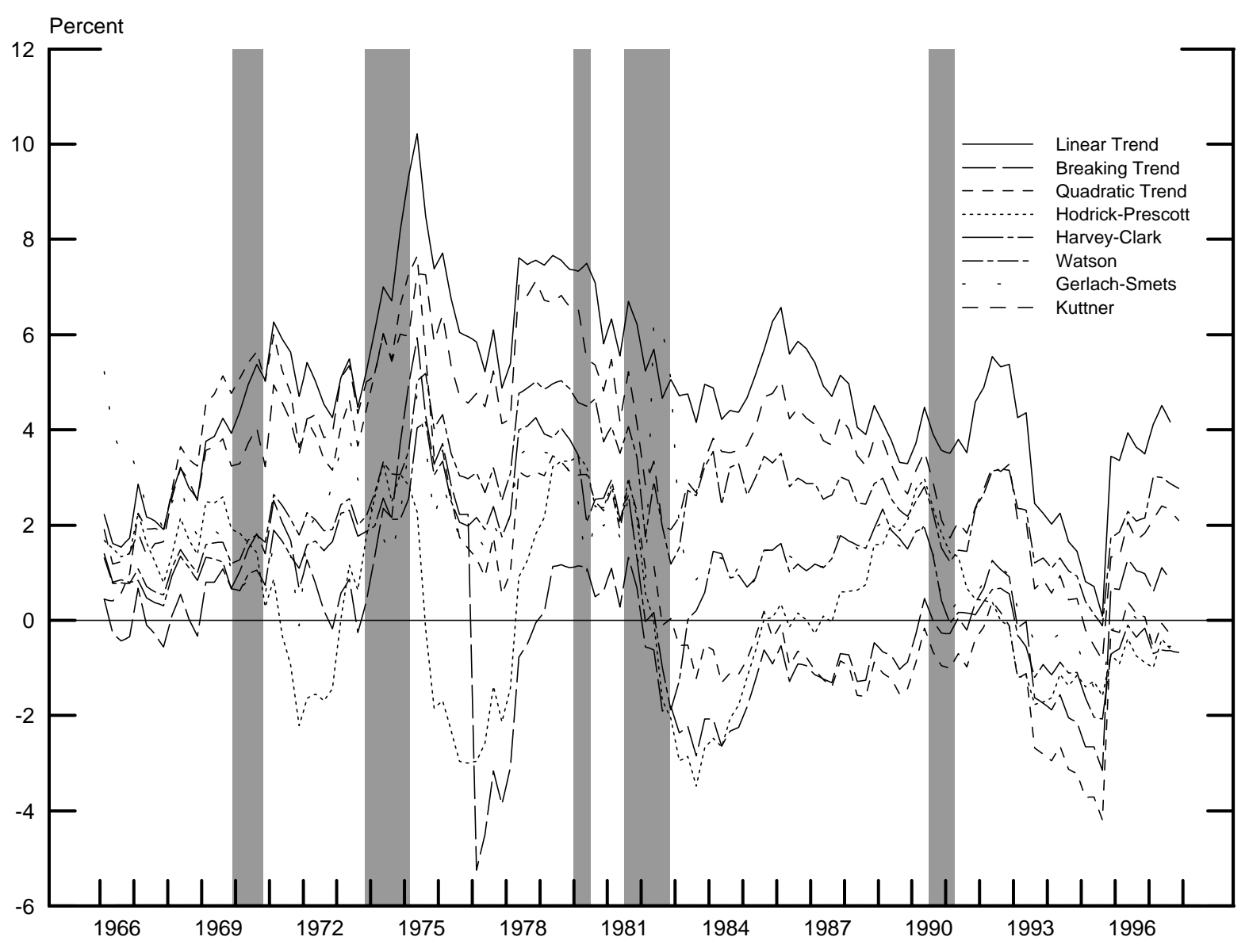


Figure 3

\section{Estimated Business Cycle: Linear Trend}

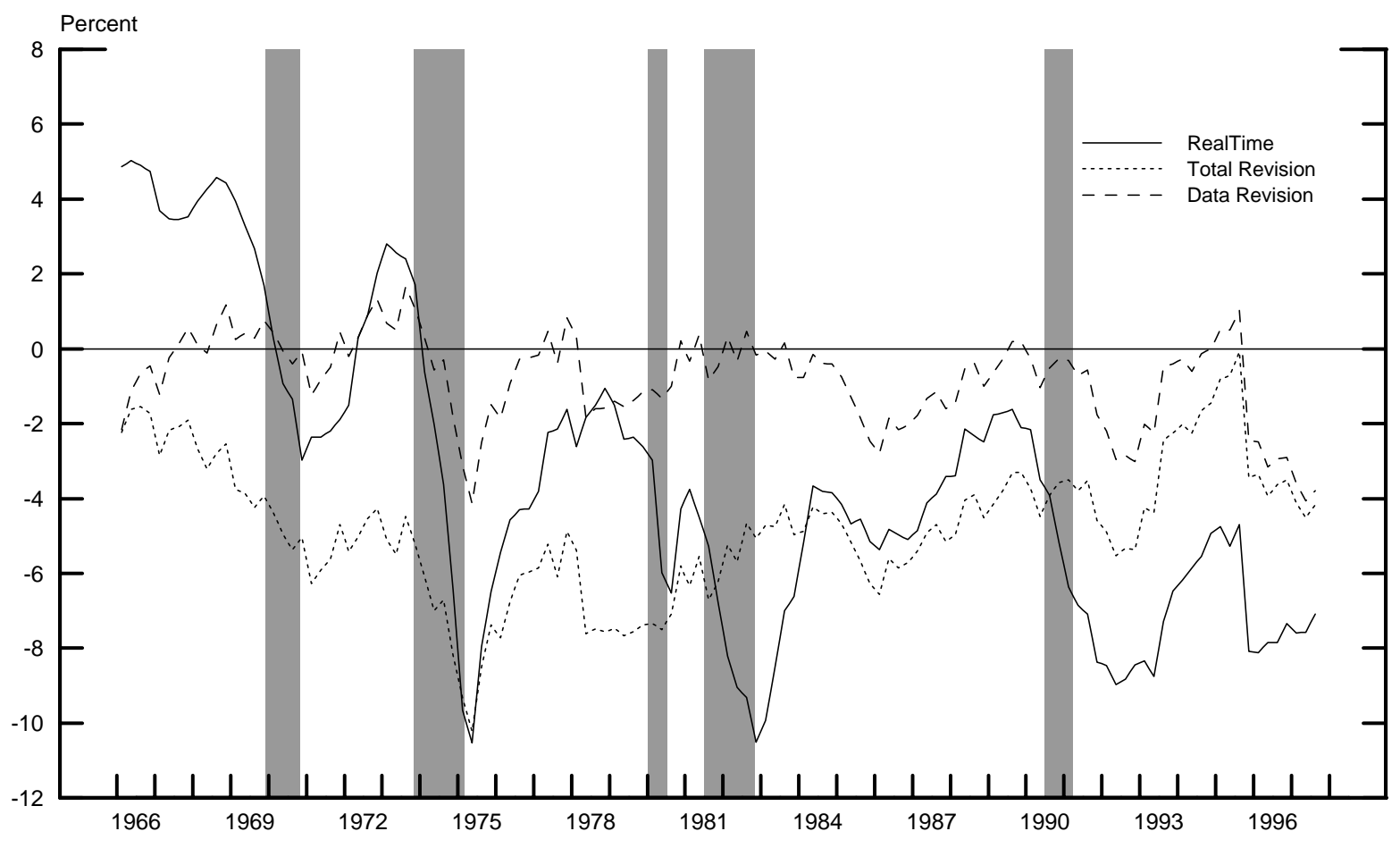


Figure 4

Estimated Business Cycle: Breaking Linear Trend

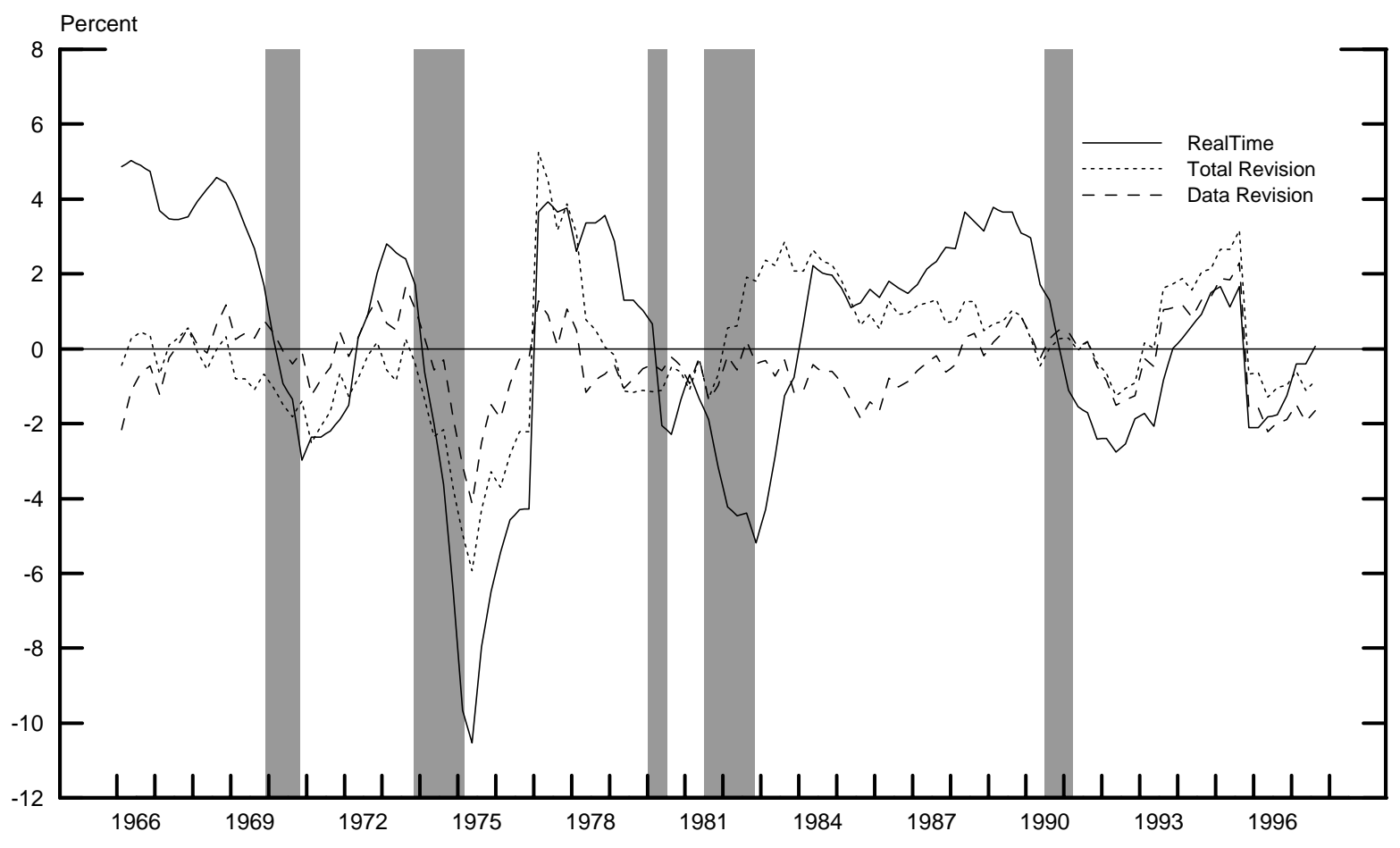


Figure 5

Estimated Business Cycle: Quadratic Trend

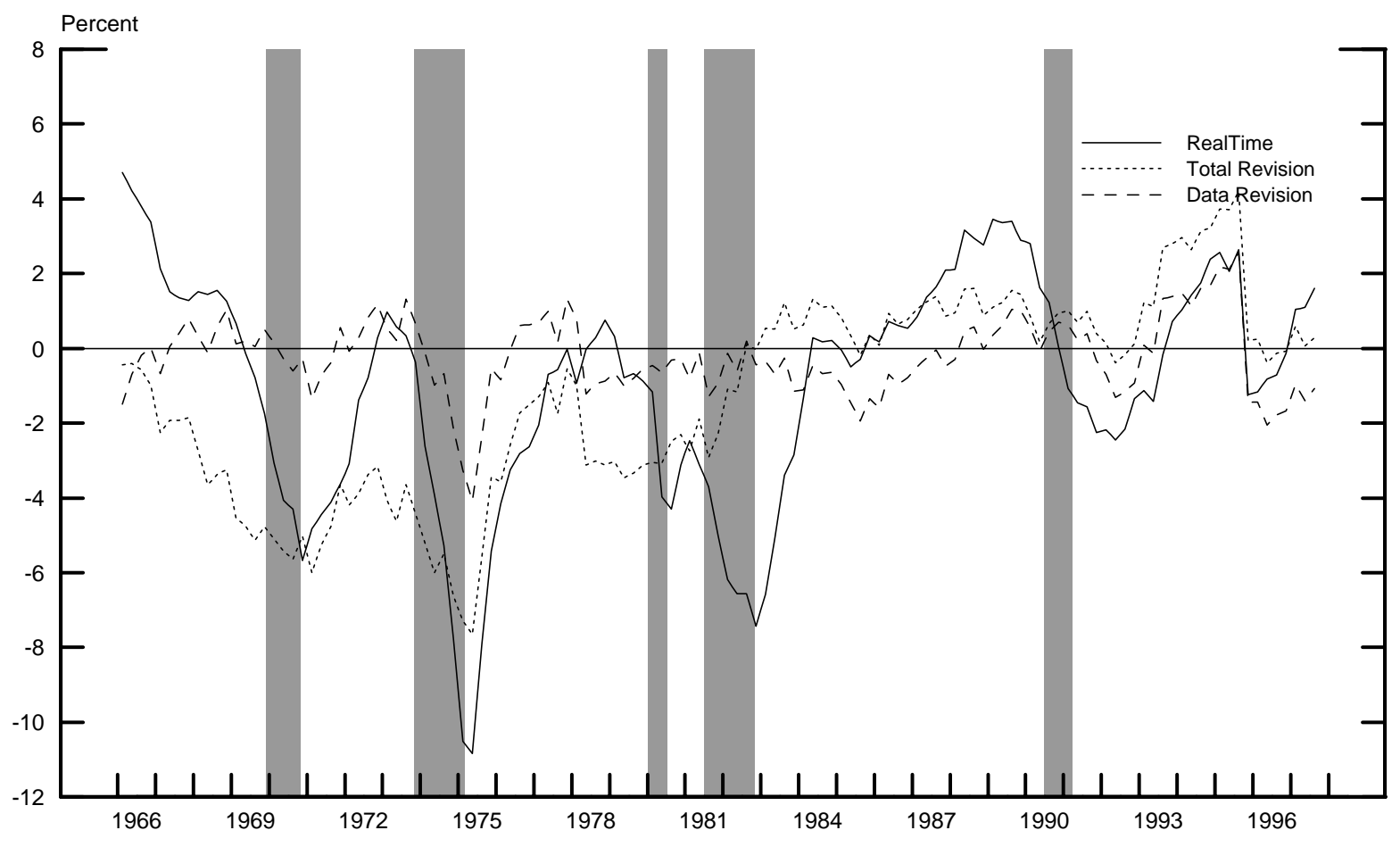


Figure 6

Estimated Business Cycle: Hodrick-Prescott

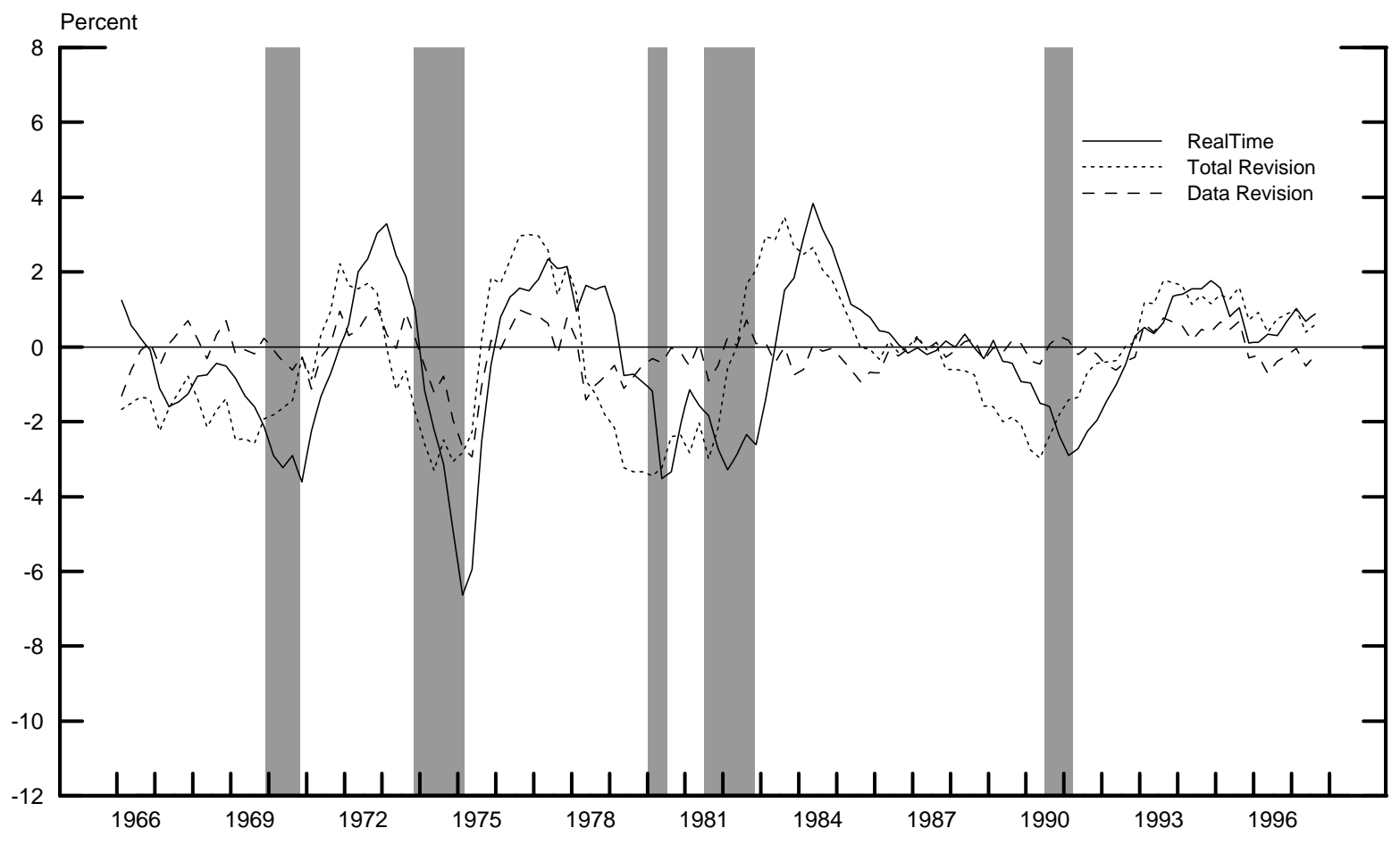


Figure 7

Estimated Business Cycle: Watson
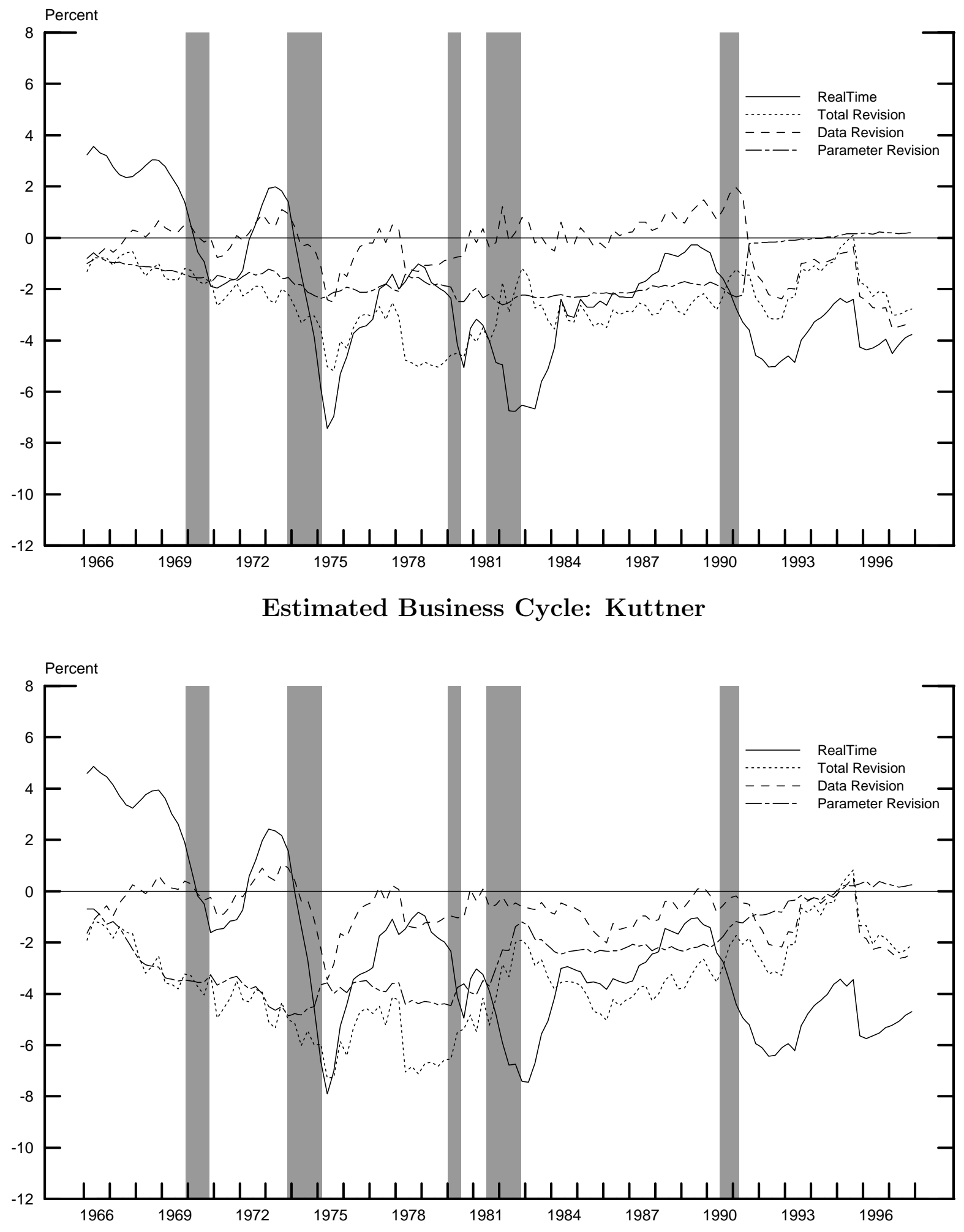
Figure 8

Estimated Business Cycle: Harvey-Clark

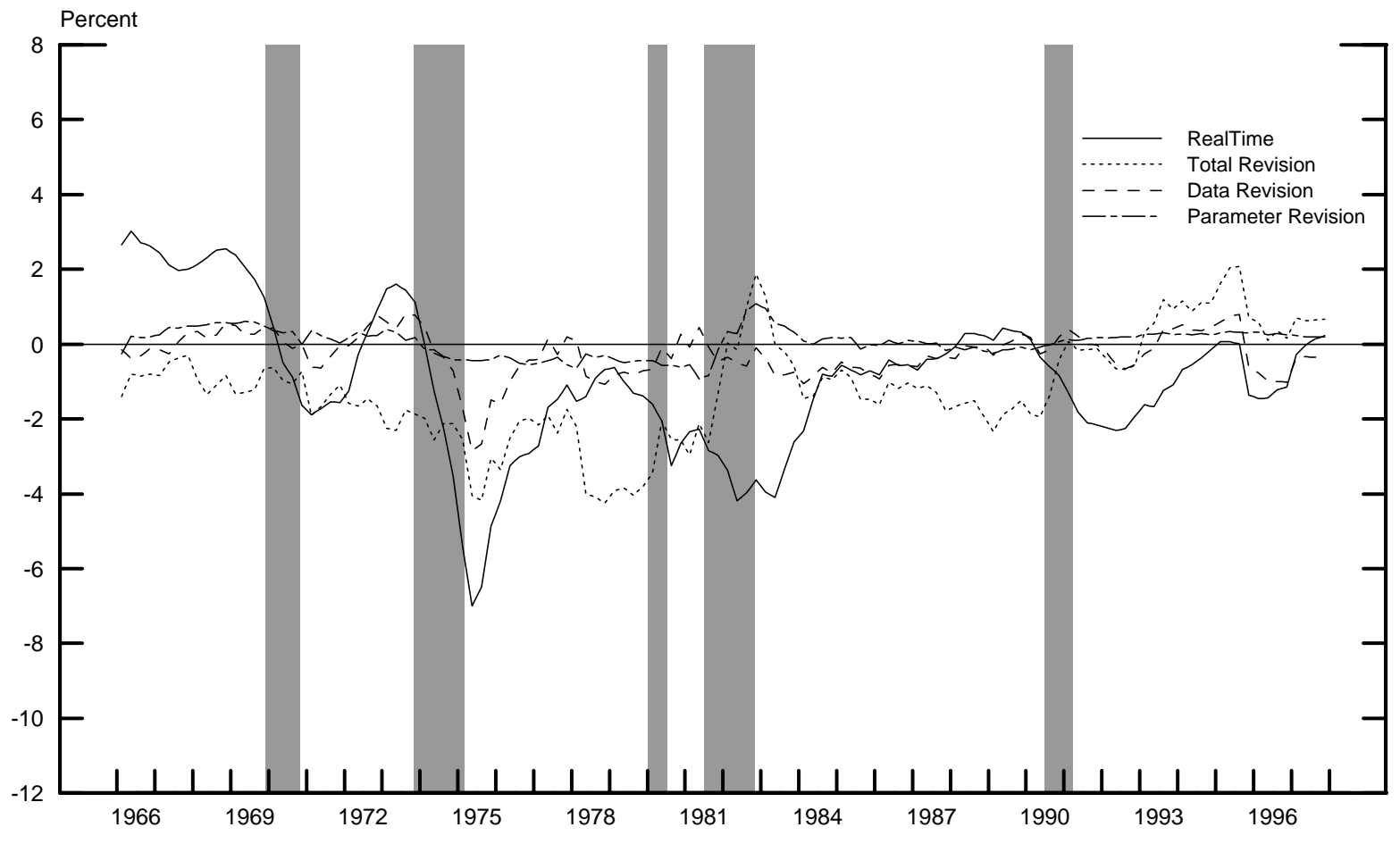

Estimated Business Cycle: Gerlach-Smets

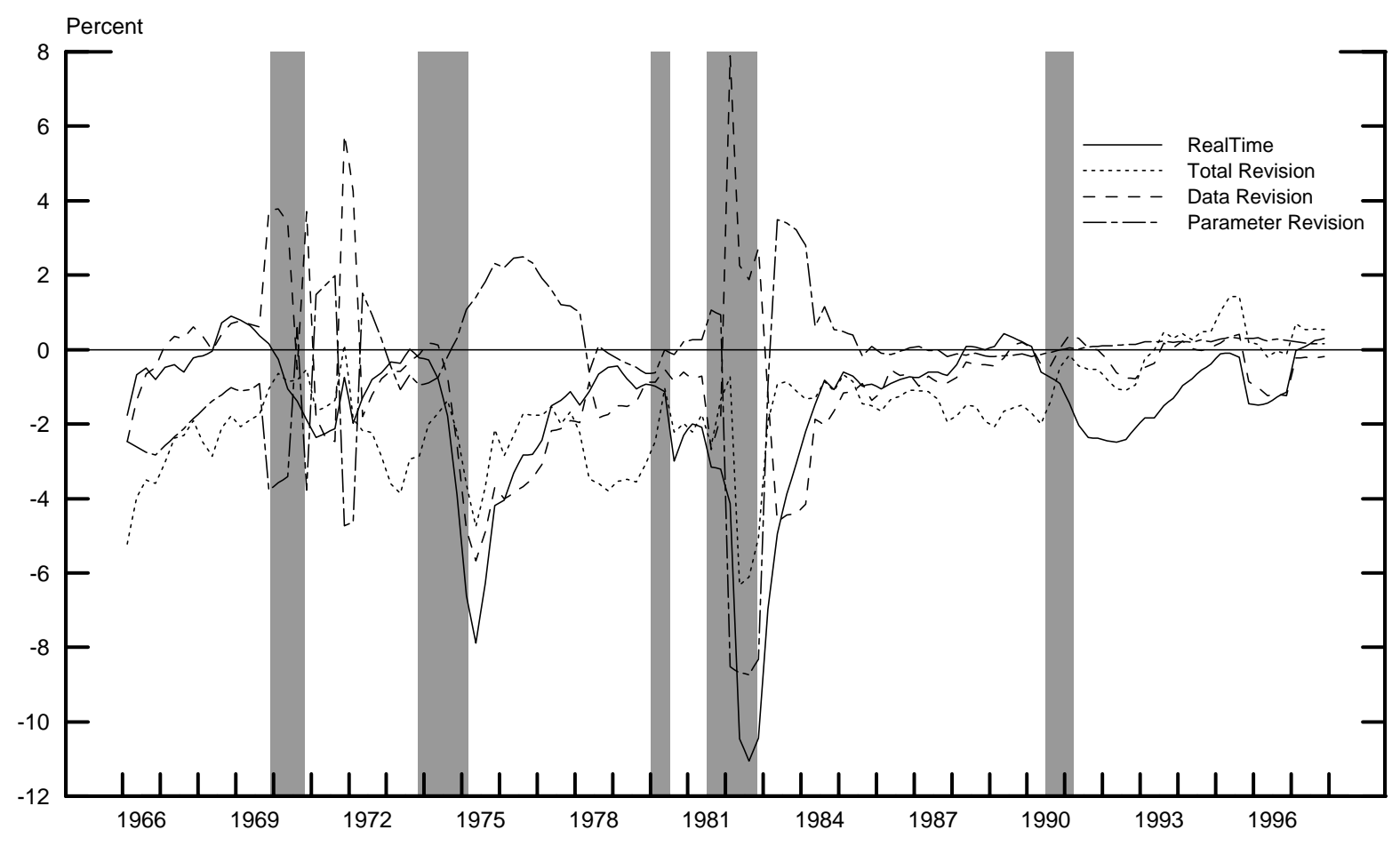


Figure 9

\section{Estimates and 95\% Confidence Intervals}

\section{Harvey-Clark}
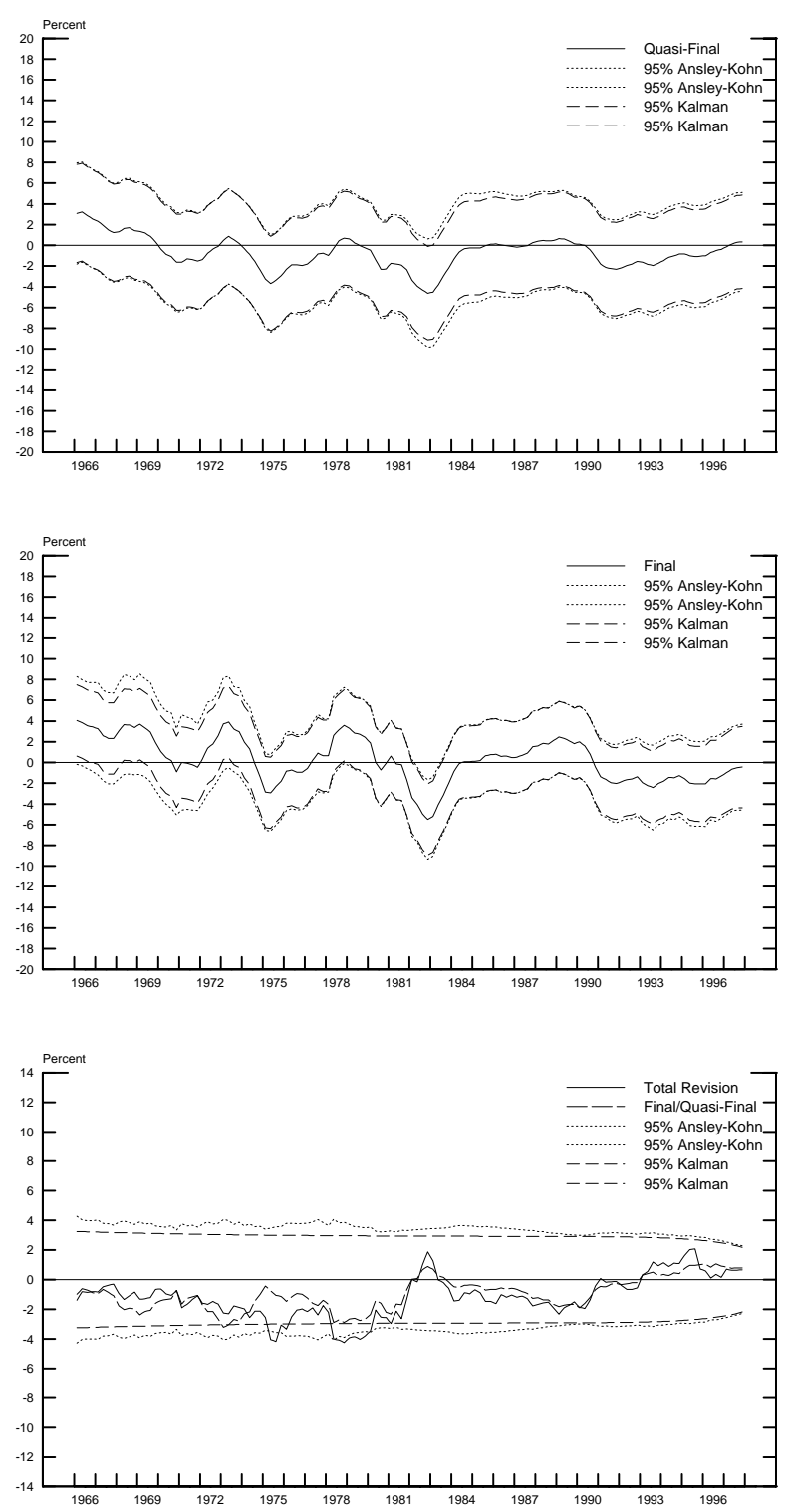

Gerlach-Smets
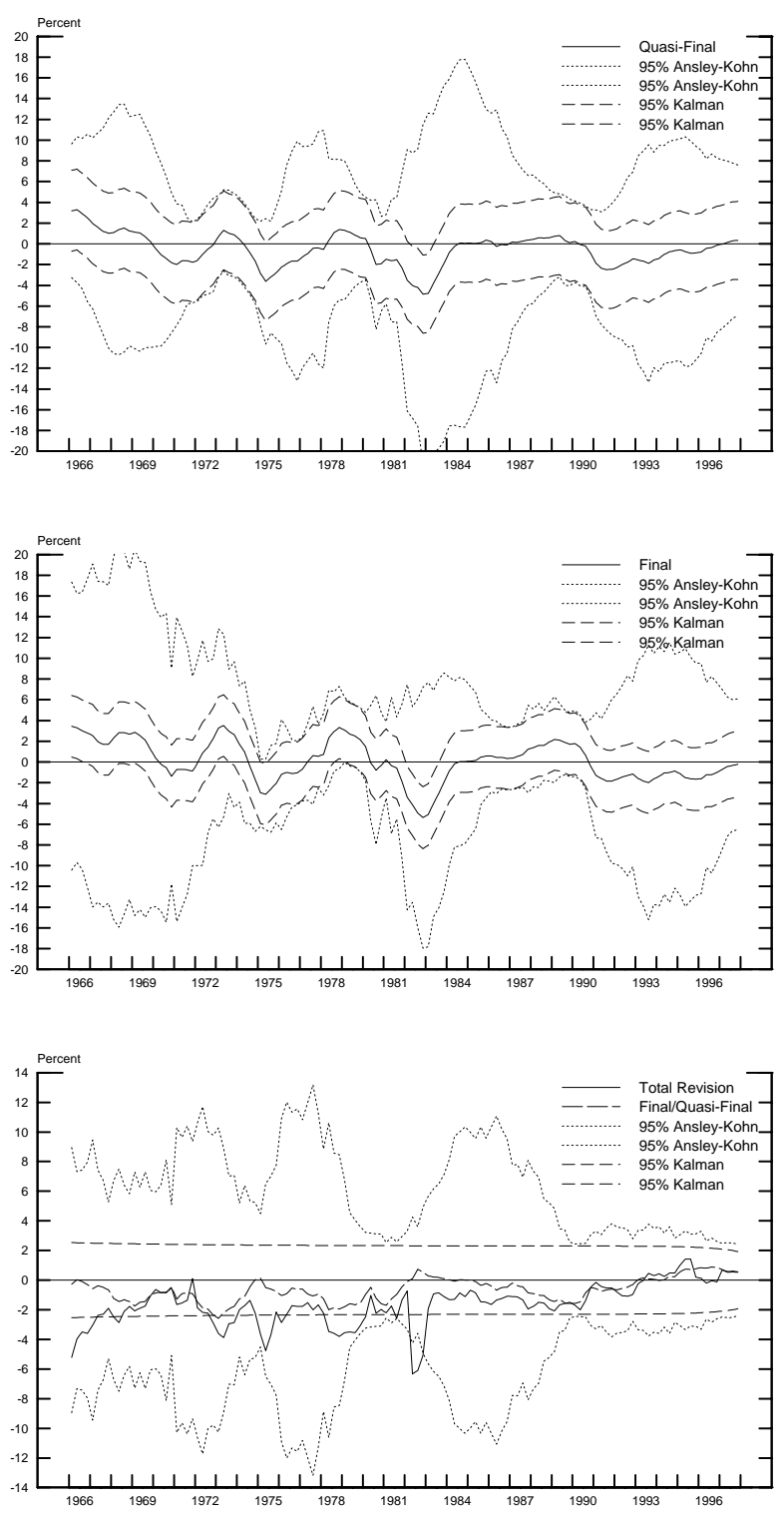

Notes: The top and middle panels show Quasi-Final and Final estimates of the output gap and the bottom panel shows the total and Final/Quasi-Final revisions for the indicated UC models. Two sets of $95 \%$ confidence intervals are also shown. Kalman is based on the Kalman filter variances assuming no parameter uncertainty. Ansley-Kohn is based on an approximation that also incorporates parameter uncertainty. 
Figure 10

\section{Estimates and 95\% Confidence Intervals}

\section{Watson}
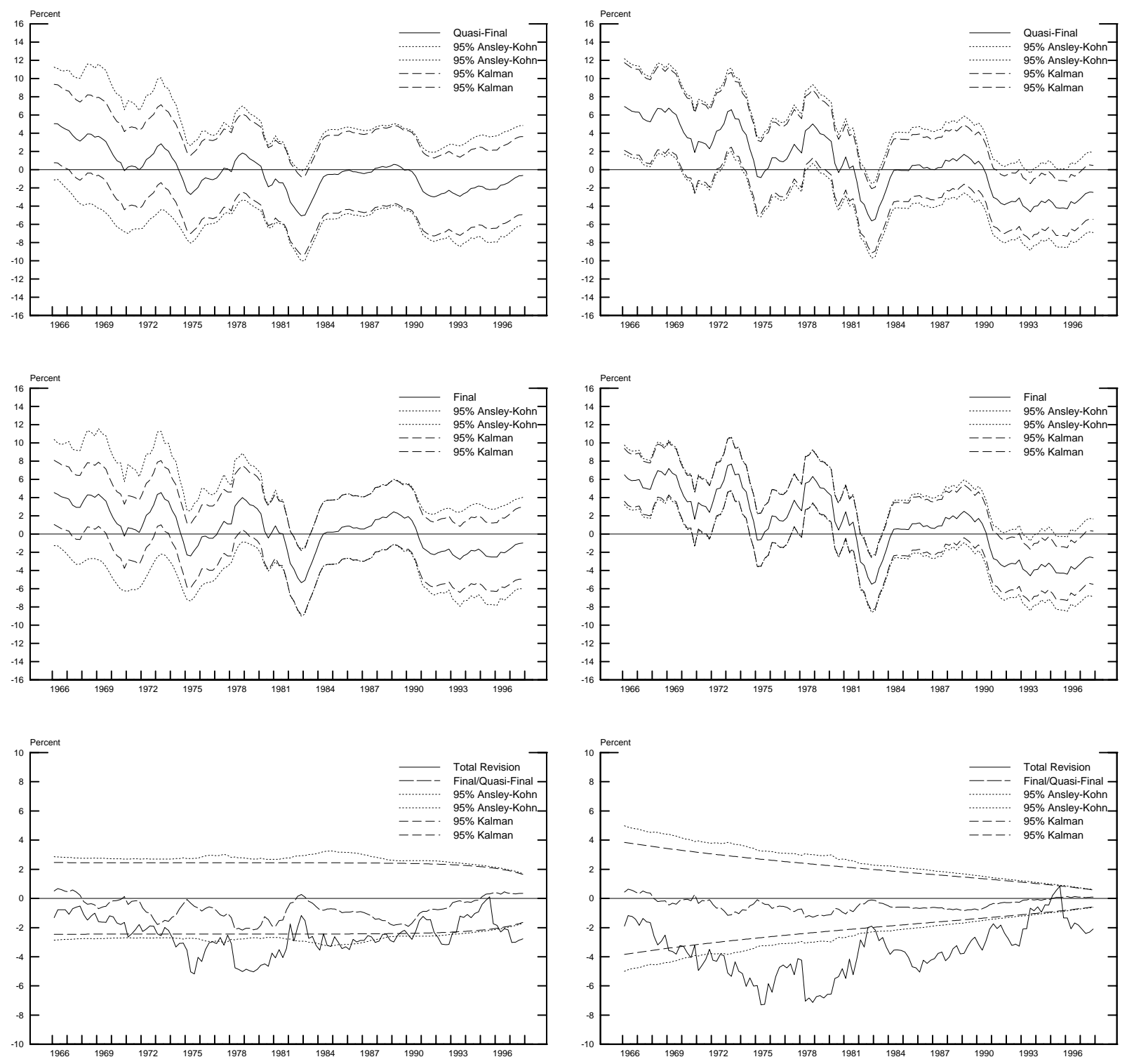

Notes: See notes to Figure 8. 


\section{Liste des publications au CIRANO*}

\section{Série Scientifique / Scientific Series (ISSN 1198-8177)}

2001s-57 The Unreliability of Output Gap Estimates in Real Time / Athanasios Orphanides et Simon van Norden

2001s-56 Exact Nonparametric Two-Sample Homogeneity Tests for Possibly Discrete Distributions / Jean-Marie Dufour et Abdeljelil Farhat

2001s-55 Les coûts de la réglementation : une revue de la littérature / Robert Gagné, Paul Lanoie, Pierre-Carl Micheud et Michel Patry

2001s-54 Testing for structural Change in the Presence of Auxiliary Models / Eric Ghysels et Alain Guay

2001s-53 Environmental Regulation and Productivity: New Findings on the Porter Hypothesis / Paul Lanoie, Michel Patry et Richard Lajeunesse

2001s-52 The Aftermarket Performance of Initial Public Offerings in Canada / Maher Kooli et Jean-Marc Suret

2001s-51 Capital Structure and Risk Management / Karine Gobert

2001s-50 The Underpricing of Initial Public Offerings: Futher Canadian Evidence / Maher Kooli et Jean-Marc Suret

2001s-49 How Innovative Are Canadian Firms Compared to Some European Firms? A Comparative Look at Innovation Surveys / Pierre Mohnen et Pierre Therrien

2001s-48 A Tale of Two Ports / Ngo Van Long et Kar-yiu Wong

2001s-47 Wage Policy of Firms: An Empirical Investigation / Stéphanie Lluis

2001s-46 Forecasting Some Low-Predictability Time Series Using Diffusion Indices / Marc Brisson, Bryan Campbell et John W. Galbraith

2001s-45 The Importance of the Loss Function in Option Pricing / Peter Christoffersen et Kris Jacobs

2001s-44 Let's Get "Real" about Using Economic Data / Peter Christoffersen, Eric Ghysels et Norman R. Swanson

2001s-43 Fragmentation, Outsourcing and the Service Sector / Ngo Van Long, Ray Riezman et Antoine Soubeyran

2001s-42 Nonlinear Features of Realized FX Volatility / John M. Maheu et Thomas H. McCurdy

2001s-41 Job Satisfaction and Quits: Theory and Evidence from the German Socioeconomic Panel / Louis Lévy-Garboua, Claude Montmarquette et Véronique Simonnet

2001s-40 Logique et tests d'hypothèse : réflexions sur les problèmes mal posés en économétrie / Jean-Marie Dufour

\footnotetext{
* Consultez la liste complète des publications du CIRANO et les publications elles-mêmes sur notre site Internet :
} 